\title{
COVID-19: EFEITOS E IMPLICAÇÕES OCORRIDOS NO TURISMO DA ROTA DAS EMOÇÕES LOCALIZADA NO NORDESTE DO BRASIL
}

\author{
Henrique César Melo Ribeiro \\ Doutor em Administração pela Universidade Nove de Julho (UNINOVE) \\ Universidade Federal do Delta do Parnaíba (UFDPar) \\ hcmribeiro@gmail.com \\ Antônia Amanda Alves Pereira Moreira \\ Mestranda em Gestão Pública pela Universidade Federal do Piauí (UFPI) \\ Universidade Federal do Piauí (UFPI) \\ amanda_alves-96@hotmail.com
}

\section{RESUMO}

Objetivo do estudo: Estudar os efeitos e as implicações ocorridas no destino turismo da Rota das Emoções localizada no Nordeste do Brasil em decorrência da pandemia do COVID-19.

Metodologia/abordagem: Metodologicamente, utilizou-se a abordagem qualitativa, mediante o método do estudo de caso múltiplo em três Empresas de Passeio (receptivos) que compõem a Rota das Emoções, Ceará, Maranhão e Piauí (uma empresa em cada estado).

Originalidade/Relevância: $O$ presente estudo enfoca o turismo da Rota das Emoções sob a óptica do COVID-19, tema este delicado que abrange, ainda hoje, a saúde humana e das empresas em todo o mundo. E que neste estudo buscou contemplar informações para a academia no que concerne especificamente o setor do Turismo do Nordeste do Brasil.

Principais resultados: Apontam os efeitos e as implicações que a pandemia do COVID-19 trouxe para a Rota da Emoções nas empresas objeto de estudo, e, consequentemente para empresas parceiras que fazem parte desse citado clusters. Conclui-se que as empresas investigadas sofreram impacto direto da pandemia, impactando em seus clientes, parceiros, receitas, resultados.

Contribuições teóricas/metodológicas: Enfatiza o tema do setor do Turismo do Nordeste do Brasil, a Rota das Emoções, e os efeitos e implicações que o citado setor sofreu em decorrência da pandemia da COVID-19.

Contribuições sociais/para a gestão: Contempla informações sobre o COVID-19, que é um tema de saúde pública que influenciou de maneira macro a sociedade, sobretudo no que concerne ao setor do Turismo da Rota das Emoções.

Palavras-chave: Turismo. COVID-19. Rota das emoções. Nordeste.

\section{Cite como}

American Psychological Association (APA)

Ribeiro, H. C. M., \& Moreira, A. A. A. P. (2021, maio/ago.). COVID-19: efeitos e implicações ocorridos no turismo da rota das emoções localizada no nordeste do Brasil. PODIUM Sport, Leisure and Tourism Review, São Paulo, 10(2), 106-138. https://doi.org/10.5585/podium.v10i2.18419. 
Ribeiro, H. C. M., \& Moreira, A. A. A. P. (2021, maio/ago.). COVID-19: efeitos e implicações ocorridos no turismo da rota das emoções localizada no nordeste do Brasil

\section{COVID-19: EFFECTS AND IMPLICATIONS FOR TOURISM ON THE ROUTE OF EMOTIONS LOCATED IN NORTHEASTERN BRAZIL}

\section{ABSTRACT}

Purpose: To study the effects and implications that occurred in the tourism destination of the Route of Emotions located in the Northeast of Brazil due to the pandemic of COVID-19.

Methodology/approach: Methodologically, the qualitative approach was used, using the multiple case study method in three Tour companies (receptive) that make up the Route of Emotions, Ceará, Maranhão and Piauí (one company in each state).

Originality/Relevance: The present study focuses on the tourism of the Route of Emotions from the perspective of COVID-19, a delicate subject that still covers human health and companies worldwide today. And that in this study sought to contemplate information for the academy regarding specifically the sector of Tourism in Northeast Brazil.

Main results: They point out the effects and implications that the pandemic of COVID-19 brought to the Route of Emotions in the companies object of study, and, consequently, for partner companies that are part of this mentioned clusters. It is concluded that the investigated companies suffered a direct impact of the pandemic, impacting their customers, partners, revenues, results.

Theoretical/methodological contributions: Emphasizes the theme of the Tourism sector in Northeast Brazil, the Route of Emotions, and the effects and implications that the mentioned sector suffered as a result of the COVID-19 pandemic.

Social contributions/for management: Includes information on COVID-19, which is a public health issue that has influenced society in a macro way, especially with regard to the Tourism sector of Rota das Emotions.

Keywords: Tourism. COVID-19. Route of emoticons. Northeast.

\section{COVID-19: EFECTOS E IMPLICACIONES OCURRIDAS EN EL TURISMO EN LA RUTA DE LAS EMOCIONES UBICADAS EN EL NORESTE DE BRASIL}

\section{RESUMEN}

Objetivo del estudio: Estudiar los efectos e implicaciones que ocurrieron en el destino turístico de la Ruta de las Emociones ubicada en el Nordeste de Brasil debido a la pandemia de COVID-19.

Metodología / enfoque: Metodológicamente, se utilizó el enfoque cualitativo, utilizando el método de estudio de casos múltiples en tres empresas de turismo (receptivas) que conforman la Ruta de las Emociones, Ceará, Maranhão y Piauí (una empresa en cada estado).

Originalidad / Relevancia: Este estudio se centra en el turismo de la Ruta de las Emociones desde la perspectiva del COVID-19, un tema delicado que aún cubre la salud humana y las empresas a nivel mundial en la actualidad. Y que en este estudio se buscó contemplar información para la academia con respecto específicamente al sector Turismo en el Nordeste de Brasil.

Principales resultados: Señalan los efectos e implicaciones que la pandemia de COVID-19 trajo a la Ruta de las Emociones en las empresas objeto de estudio y, en consecuencia, para las empresas colaboradoras que forman parte de estos clusters mencionados. Se concluye que las empresas investigadas sufrieron un impacto directo de la pandemia, impactando a sus clientes, socios, ingresos, resultados.

Aportes teórico-metodológicos: Destaca el tema del sector Turismo en el Nordeste de Brasil, la Ruta de las Emociones, y los efectos e implicaciones que sufrió el mencionado sector como consecuencia de la pandemia de COVID-19.

Contribuciones sociales / de gestión: Incluye información sobre COVID-19, que es un problema de salud pública que ha influido de manera macro a la sociedad, especialmente en lo que respecta al sector Turismo de Rota das Emotions.

Palabras clave: Turismo. COVID-19. Ruta de las emociones. Noreste. 
Ribeiro, H. C. M., \& Moreira, A. A. A. P. (2021, maio/ago.). COVID-19: efeitos e implicações ocorridos no turismo da rota das emoções localizada no nordeste do Brasil

\section{Introdução}

O novo coronavírus (COVID-19) está desafiando o mundo, pois, até o presente momento (desde a elaboração deste artigo em julho 2020) não existe vacina. Com isso, a capacidade médica é limitada para tratar a doença, e as intervenções não farmacêuticas são a principal estratégia para conter a pandemia. Posto isto, as restrições globais de viagens sem precedentes e o isolamento social vem causando a perturbação mais grave da economia global desde o mundo pós Segunda Guerra Mundial (Senhoras \& Nascimento, 2020; Trigo, 2020).

Neste panorama, salienta-se que, com as proibições internacionais de viagens que afetaram mais de $90 \%$ da população mundial, ou seja, a mobilidade comunitária, o setor do turismo cessou em grande parte do mundo em março de 2020 (Gossling, Scott \& Hall, 2020). Nesse sentido, entende-se que o setor do turismo é especialmente suscetível a medidas para combater a pandemia do COVID-19 no que se refere à mobilidade restrita e o distanciamento social (Bezerra et al., 2020; Gossling, Scott \& Hall, 2020).

Neste modo, os impactos do COVID-19 em países emergentes serão desproporcionalmente consideráveis, e, com isso, tais países terão que aprender coletivamente com essa tragédia global para mitigar as implicações e as mudanças de suas localidades mais propensas ao turismo (Carbone, 2020; Coelho \& Mayer, 2020; Farzanegan, et al., 2020; Gossling, Scott \& Hall, 2020). Constata-se assim uma influência do COVID-19 no setor do turismo (Romão, 2020; Sayfullaev, 2020). Tal constatação pôde ser vista e sentida no final de março de 2020 com a expansão da pandemia no mundo, paralisando sistemas de saúde, os sistemas globais de viagens aéreas, marítimas, terrestres, o setor de eventos e diversões públicas, dentre outras (Trigo, 2020).

Em suma, surtos de doenças e pandemias têm desempenhado um papel importante nas mudanças e nos resultados sociais e econômicos. Contudo, a natureza de tais efeitos e transformações é seletiva, o que significa que às vezes é mínima e, outras vezes, que tais efeitos e transformações podem ser potencialmente inesperadas reforçando os paradigmas contemporâneos (Hall, Scott \& Gössling, 2020). Reforça-se novamente o impacto da COVID19 no sistema global de viagens e turismo, truncando-o, e, levando-o a uma imensa crise nunca vista, desde a Segunda Guerra Mundial (Trigo, 2020), podendo ser constatada de maneira tangível em todas as regiões do Brasil, mediante a redução do PIB do setor turístico, incorrendo em uma grave crise empresarial, o que culminou no fechamento de muito empreendimentos da área do turismo e aqueles que dão suporte à área (Souza, 2021). 
Ribeiro, H. C. M., \& Moreira, A. A. A. P. (2021, maio/ago.). COVID-19: efeitos e implicações ocorridos no turismo da rota das emoções localizada no nordeste do Brasil

Diante disso, surge à questão de pesquisa que norteará este estudo: Que efeitos e implicações ocorreram no destino Turismo da Rota das Emoções localizada no Nordeste do Brasil em decorrência da pandemia do COVID-19? Objetivo: Estudar os efeitos e as implicações ocorridas no destino turismo da Rota das Emoções localizada no Nordeste do Brasil em decorrência da pandemia do COVID-19. A escolha pela região do Nordeste para efetuar este estudo foi devido a duas condições: (i) medidas formuladas para a redução dos impactos do COVID-19 foram descontextualizadas às condições socioeconômicas da população da citada região e que tem no turismo um dos pilares da sua economia; e (ii) a região do Nordeste é a mais procurada até então, pelos brasileiros em viagens domésticas, consumadas na alta temporada e ou durante as férias escolares (Souza, 2021).

Enfatiza-se que a Rota das Emoções é um percurso de 900 quilômetros de estrada que inclui atrações turísticas de três Estados: Ceará, Maranhão e Piauí. Ao visitar os três estados é possível se deparar com similaridades e diferenças que cada região apresenta. Inúmeras empresas de seguimentos distintos como agências, receptivos (empresas de passeio), hotéis, pousadas, dentre outras, que trabalham diariamente para movimentar a economia da Rota das Emoções que é referência no Nordeste (Costa, Nascimento, Hoffmann \& Silva, 2017; Silva, Hoffmann \& Costa, 2020).

Levou-se a estudar o setor do turismo em decorrência deste: (i) ter tido uma rápida progressão pelo mundo; (ii) existir rotas turísticas internacionais espalhadas; e (iii) contemplar empresas em cadeia, como no caso das redes hoteleiras (Costa, Nascimento, Hoffmann \& Silva, 2017; Sayfullaev, 2020).

Também por entender ser importante estudar o processo de desenvolvimento e os efeitos de pandemias, fornecendo a posteriori achados úteis para trabalhos científicos subsequentes (Zhan et al., 2019). Com isso, esta pesquisa contribuirá para ajudar aos gestores do Turismo a tomar precauções e para implementar e adotar estratégias (Ribeiro \& Forte, 2019) para o futuro do setor (Karim, Haque \& Anis, 2020).

Justifica-se a escolha do destino turístico (Gomes, Gândara \& Ivars-Baidal, 2017) da Rota das Emoções em virtude deste ser integrado por três estados que compõem a região Nordeste do Brasil (Ceará, Piauí e Maranhão). E os seus roteiros turísticos respectivos são: Jericoacoara (CE), Delta do Parnaíba (PI) e Barreirinha (MA). Este é o primeiro consórcio interestadual de turismo do Brasil provendo de variáveis de localização considerada operacionalizada (Silva, Hoffmann \& Costa, 2020), reunindo clusters de empresas com 
Ribeiro, H. C. M., \& Moreira, A. A. A. P. (2021, maio/ago.). COVID-19: efeitos e implicações ocorridos no turismo da rota das emoções localizada no nordeste do Brasil

relações de complementariedade (Mazaro \& Varzin, 2008; Sohn, Silvestrini, Fiuza \& Limberger, 2017).

Santos, Ribeiro e Silveira (2018) confirmam em seu estudo, que Jericoacoara e os Lençóis Maranhenses estão entre os principais clusters turísticos do Nordestes e, consequentemente do Brasil, justificando assim a escolha destes destinos turísticos. Já o Delta do Parnaíba é justificável também sua escolha em decorrência deste ter crescido substancialmente como destino turístico no Nordeste nos últimos anos (Melo, Monteiro \& Brito, 2018).

Este estudo possui caráter de ineditismo, no contexto brasileiro, por contemplar os efeitos e as implicações da crise do COVID-19 no setor do Turismo da Rota das Emoções nos estados do CE, MA e PI nas empresas de passeio do setor, auxiliando e contribuindo com isso no melhor entendimento e compreensão desse acontecimento para enfrentá-lo, criando uma agenda de pesquisa, e gerando assim oportunidades de surgimento de novas pesquisas análogas, alargando e robustecendo os conhecimentos sobre este fenômeno que nos aflige neste momento.

Esta pesquisa está dividida em cinco seções. A primeira aborda a introdução com a justificativa, questão, objetivo e contribuição do estudo, seguido do referencial teórico. Os procedimentos metodológicos são enfocados na parte três deste estudo. $\mathrm{Na}$ seção quatro evidencia-se a análise e a discussão dos resultados. E, por fim, na quinta seção são realçadas as considerações finais, com os resultados, contribuições, conclusões, limitação e sugestões para estudos futuros.

\section{Referencial teórico}

Esta sessão abordará temas importantes nos quais envolvem COVID-19 e turismo, abordando conceitos e teorias para fins de estudo, procurando dar as bases que sustentarão ao processo de pesquisa.

\subsection{COVID-19 e turismo}

A doença do novo coronavírus (COVID-19) causada pelo vírus SARS-CoV-2 (Lima et al., 2020; Marivate \& Combrink, 2020) foi identificada pela primeira vez na cidade de Wuhan, província de Hubei, na China em dezembro de 2019, recebendo logo após uma substancial atenção no âmbito global (Zhai \& Du, 2020).

A doença do COVID-19 se espalhou rapidamente em todo o mundo, apresentando enormes desafios para os sistemas de saúde, econômicos e sociais. Como não existem 
Ribeiro, H. C. M., \& Moreira, A. A. A. P. (2021, maio/ago.). COVID-19: efeitos e implicações ocorridos no turismo da rota das emoções localizada no nordeste do Brasil

medicamentos e vacinas comprovadas para o tratamento do COVID-19, medidas não farmacêuticas (Nicola et al., 2020) essenciais foram adotadas e praticadas para retardar a propagação desta pandemia (Kuwahara, Kuroda \& Fukuda, 2020).

Posto isto, o distanciamento social é uma parte essencial da medida de saúde pública para controle desta infecção. Diante do contexto, muitos eventos e atividades sociais foram cancelados ou reduzidos em muitos países (Kuwahara, Kuroda \& Fukuda, 2020), como no caso do Brasil, onde já existe um número alto de casos do COVID-19 (Ministério da Saúde, 2020).

$\mathrm{Na}$ pesquisa de Manchein, Brugnago, Silva, Mendes e Beims (2020) os autores analisaram o crescimento do número acumulado de casos confirmados de infecção pelo COVID-19 em países dos continentes Ásia, Europa, América do Norte e América do Sul. Tal estudo concluiu que o isolamento social das pessoas é a principal estratégia, até o momento, para se conseguir achatar a curva de infecção do vírus e mortes (Manchein et al., 2020).

Entende-se que o COVID-19 trouxe distanciamento social e restrição de aglomerações, fazendo com que vários setores trabalhassem em capacidade operacional reduzida e em diversos casos gerando o fechamento temporário de vários negócios (Soares \& Mazon, 2020). Este isolamento social afetou organizações, como as empresas de turismo (Gossling, Scott \& Hall, 2020; Sheresheva, 2020). Em suma, o mundo sofreu uma série de grandes epidemias / pandemias nos últimos 40 anos, mas nenhuma dessas teve implicações semelhantes para o Turismo, e, consequentemente para a economia como a pandemia do COVID-19.

Aguiar e Melo (2020) complementam ao afirmar que antes do COVID-19, que se espalhou pelo mundo, em 2020, a expectativa da demanda turística, era de crescimento global, neste ano, sobretudo para destinos turísticos mais maduros. Contudo, está estimação está fadada ao insucesso, em virtude das medidas de isolamento social e fechamento do comércio e equipamentos turísticos, por muitos países, inclusive no Brasil.

$\mathrm{O}$ isolamento social acaba por impor, uma situação de contraponto com um dos principais fins do turismo que é ofertar serviços de turismo, utilizando mão-de-obra local. Desse modo, o termo sustentabilidade tem estado presente nos discursos das organizações de diversos segmentos, que buscam justificar os impactos das diferentes atividades produtivas e de serviços sobre o meio ambiente e legitimar sua atuação social (Froehlich, 2014), atuação social essa que em tempos de pandemia, fica reduzida e em muitos locais temporariamente suspensa.

Entretanto, existem destinos turísticos populares em tempo integral como as Ilhas do Pacífico (Tonga, Samoa, Vanuatu, Ilhas Cook, Niue e Tuvalu), que até o presente momento não 
Ribeiro, H. C. M., \& Moreira, A. A. A. P. (2021, maio/ago.). COVID-19: efeitos e implicações ocorridos no turismo da rota das emoções localizada no nordeste do Brasil

foram tocadas pelo COVID-19. Isso ocorre em razão de seu forte isolamento e afastamento social (Acter, Uddin, Das, Akhter, Choudhury e Kim, 2020).

Explica-se, pois, o COVID-19 não é tão contagioso quanto o sarampo e não é tão letal a uma pessoa infectada quanto o Ebola, mas as pessoas podem começar a propagar o vírus do COVID-19 vários dias antes dos sintomas surgirem (Gossling, Scott \& Hall, 2020). Posto isto, constata-se que o COVID-19 impactou diretamente o setor do Turismo (Figueira, Baptista, Santos \& Dionísio, 2020), levando-o quase ao desastre (Sheresheva, 2020), sobretudo para os países que dependem deste setor como uma das fontes básicas para economia (Menegaki, 2020), como é o caso do Brasil (Oliveira \& Arantes, 2020).

O setor de turismo é formado por empresas provedoras de serviços, como os meios de hospedagem, agências de viagens, empresas de passeio dentre outros (Sarquis, Pizzinatto, Giuliani \& Pontes, 2015; Volpi \& Paulino, 2019), exercendo assim um grande papel no desenvolvimento global se correlacionando com o crescimento da economia (Khan, Hassan, Fahad \& Naushad, 2020). Fatores como: cultura, paz, segurança, infraestrutura, os vistos, atitude das pessoas, educação, nível de renda, preço das commodities, idiomas, hotéis, viagens e os destinos turísticos de cada país influenciam na economia destes (Khan, Hassan, Fahad \& Naushad, 2020).

As características estruturais de um destino turístico são de importância crucial, uma vez que influenciam seu comportamento dinâmico (Gomes, Gândara \& Ivars-Baidal, 2017). Posto isto, constata-se que os destinos são estruturalmente semelhantes, e indiscutivelmente tem características universais. Esse achado é importante, pois sugere que existem algumas estratégias muito básicas (e consistentes) que os gestores de destinos turísticos podem desenvolver ao projetar planos e iniciativas (Baggio, 2020). No decorrer dos últimos anos haviam sinais de que o turismo vinha se transformando, com a preocupação dos impactos sociais e ambientais, valorização do ecoturismo, prioridade por produtos locais e regionais, implantação de programas e investimentos para redução de consumo e desperdício de água e energia, responsabilidade social, gestão de resíduos entre outros exemplos na mesma direção. (Garkalins, 2020). Tendo os destinos turísticos papel importante na implantação e desenvolvimento destas iniciativas.

Destinos turísticos são regiões geográficas que oferecem produtos (Caldeira, 2013) e serviços turísticos interligados (Vieira, Hoffmann \& Alberton, 2018). E a competitividade do turismo relaciona-se com os destinos turísticos, sobretudo com os novos que surgem (Santos \& Ribeiro, 2016). 
Ribeiro, H. C. M., \& Moreira, A. A. A. P. (2021, maio/ago.). COVID-19: efeitos e implicações ocorridos no turismo da rota das emoções localizada no nordeste do Brasil

\section{Procedimentos metodológicos}

O objetivo desta pesquisa foi estudar os efeitos e as implicações ocorridas no destino turismo da Rota das Emoções localizada no Nordeste do Brasil em decorrência da pandemia do COVID-19. Diante disso, a referida pesquisa será do tipo exploraria, em decorrência desta ser propicia para ajudar a responder questões de pesquisa com pouco aprofundamento do conhecimento científico (Gouvêa, Onusic \& Mantovani, 2016).

Para tanto, utilizar-se-á o método de estudo de caso, em decorrência deste ser especialmente usado em instantes em que o tema é embrionário na academia, e quando se faz a inter-relação entre dois assuntos (Castro, Diniz, Duarte, Dressler \& Carvalho, 2013) como é o caso do COVID-19 e o Turismo. Reforça-se e reitera-se também que para esta pesquisa, utilizarse-á as Empresas de Passeio da Rota das Emoções, e devido a isso, este trabalho científico usará o estudo de caso múltiplo. Em suma, este estudo será de natureza qualitativa, descritivo e exploratório (Cunha, Sá de Abreu \& Cruz, 2015).

É importante salientar que o estudo de caso deve atender três qualidades: (i) a questão de pesquisa proposta deve iniciar com: "como" ou "porque" ou "o que"; (ii) o pesquisador quase nunca tem controle sobre os eventos; e (iii) a pesquisa enfoca sobre fenômenos contemporâneos (Godoy, 2006; Yin, 2010; Marques, Camacho \& Alcantara, 2015). Tais condições são vislumbradas e atendidas neste estudo.

Justifica-se o uso do estudo de caso para esta pesquisa em virtude deste ser o método mais aceito em pesquisas qualitativas, que é o caso deste estudo, e, ter relação direta com estudos organizacionais (Lacruz, Américo \& Carniel, 2017), que é o foco deste trabalho científico por enfocar nas organizações de médio e pequeno porte no setor do turismo.

\subsection{Procedimentos de coleta de dados}

Para a realização deste estudo, a coleta de dados se deu por meio de entrevistas semiestruturada, documentos e observação não participante. Justifica-se o uso destes procedimentos de coleta de dados em decorrência destes serem os mais usados em pesquisas com método de estudo de caso com foco em organizações (Lacruz, Américo \& Carniel, 2017; Durante, Veloso, Machado, Cabral \& Santos, 2019).

As entrevistas são um importante meio de informação para o método do estudo de caso (Barros \& Campomar, 2018). É importante salientar que, as entrevistas são norteadas pelo roteiro das entrevistas (Quadro 1), e, consequentemente estas entrevistas (Souza \& Carrieri, 
Ribeiro, H. C. M., \& Moreira, A. A. A. P. (2021, maio/ago.). COVID-19: efeitos e implicações ocorridos no turismo da rota das emoções localizada no nordeste do Brasil

2011) são conduzidas, embasadas, alicerçadas e criadas com o apoio do referencial teórico (Castro, Bulgacov \& Hoffmann, 2011). Ressalta-se que para a construção das entrevistas, esta pesquisa enfocou-se neste protocolo.

Quadro 1 - Roteiro das entrevistas

\begin{tabular}{|c|c|c|}
\hline \multicolumn{2}{|r|}{ Perguntas } & Fonte \\
\hline 1 & O que você entende do novo coronavírus (COVID-19)? & $\begin{array}{l}\text { (Marivate \& Combrink, 2020; Zhai } \\
\& \text { Du, 2020) }\end{array}$ \\
\hline 2 & $\begin{array}{l}\text { O que você acha do distanciamento social, como } \\
\text { estratégia primordial, para o controle e achatamento a } \\
\text { posteriori da curva de infecção do COVID-19? }\end{array}$ & $\begin{array}{l}\text { (Gossling, Scott \& Hall, 2020; } \\
\text { Kuwahara, Kuroda \& Fukuda, 2020; } \\
\text { Manchein et al., 2020) }\end{array}$ \\
\hline 3 & $\begin{array}{c}\text { Que implicações o isolamento social, em decorrência da } \\
\text { pandemia, teve para o setor de Turismo no Mundo, em } \\
\text { especial para o Brasil? }\end{array}$ & $\begin{array}{l}\text { (Gossling, Scott \& Hall, 2020; } \\
\text { Sheresheva, 2020) }\end{array}$ \\
\hline 4 & $\begin{array}{c}\text { Você acha que países que dependem do Turismo, como } \\
\text { é o caso do Brasil, irão sofrer impactos catastróficos no } \\
\text { referido setor? Por quê? }\end{array}$ & $\begin{array}{l}\text { (Menegaki, 2020; Oliveira \& } \\
\text { Arantes, 2020; Sheresheva, 2020) }\end{array}$ \\
\hline 5 & $\begin{array}{l}\text { Que expectativas de crescimento econômico o setor do } \\
\text { Turismo no Brasil tinha antes da pandemia? E pós } \\
\text { pandemia? }\end{array}$ & (Aguiar \& Melo, 2020) \\
\hline 6 & $\begin{array}{l}\text { Que projeções de demanda turística as empresas do } \\
\text { Nordeste tinham antes da pandemia? E pós pandemia? }\end{array}$ & $\begin{array}{l}\text { (Santos, Ribeiro \& Silveira, 2018; } \\
\text { Aguiar \& Melo, 2020; Menegaki, } \\
\text { 2020; Oliveira \& Arantes, 2020; } \\
\text { Sheresheva, 2020; Silva, Hoffma|nn } \\
\text { \& Costa, 2020) }\end{array}$ \\
\hline 7 & $\begin{array}{l}\text { Que prospecções de demanda e crescimento turístico as } \\
\text { empresas localizadas na Rota das Emoções tinham antes } \\
\text { da pandemia? E pós pandemia? }\end{array}$ & $\begin{array}{l}\text { (Santos, Ribeiro \& Silveira, 2018; } \\
\text { Aguiar \& Melo, 2020; Menegaki, } \\
\text { 2020; Oliveira \& Arantes, 2020; } \\
\text { Sheresheva, 2020; Silva, Hoffma|nn } \\
\text { \& Costa, 2020) }\end{array}$ \\
\hline 8 & $\begin{array}{l}\text { Que tipos de empresas do setor do turismo do destino da } \\
\text { Rota das Emoções estão sofrendo mais com a } \\
\text { pandemia? E pós pandemia? }\end{array}$ & $\begin{array}{l}\text { (Volpi \& Paulino, 2019; Aguiar \& } \\
\text { Melo, 2020; Khan, Hassan, Fahad \& } \\
\text { Naushad, 2020; Menegaki, 2020; } \\
\text { Oliveira \& Arantes, 2020; } \\
\text { Sheresheva, 2020) }\end{array}$ \\
\hline 9 & $\begin{array}{l}\text { Você entende que as características do destino turismo, } \\
\text { como no caso da região geográfica na qual está } \\
\text { localizada e sua competitividade, podem ajudar na } \\
\text { recuperação destes pós pandemia? Por quê? }\end{array}$ & $\begin{array}{l}\text { (Santos \& Ribeiro, 2016; Vieira, } \\
\text { Hoffmann \& Alberton, 2018; } \\
\text { Aguiar \& Melo, 2020; Menegaki, } \\
\text { 2020; Oliveira \& Arantes, 2020; } \\
\text { Sheresheva, 2020) }\end{array}$ \\
\hline 10 & $\begin{array}{l}\text { Ao constatar que a Rota das Emoções é um consórcio } \\
\text { interestadual de turismo, o qual reuni clusters de } \\
\text { empresas com relações de complementariedade. Tal fato } \\
\text { é essencial para a recuperação deste destino pós } \\
\text { pandemia? Por quê? }\end{array}$ & $\begin{array}{l}\text { (Aguiar \& Melo, 2020; Menegaki, } \\
\text { 2020; Oliveira \& Arantes, 2020; } \\
\text { Sheresheva, 2020; Silva, Hoffmann } \\
\text { \& Costa, 2020) }\end{array}$ \\
\hline 11 & $\begin{array}{c}\text { Que estratégias as empresas que compõem a Rota das } \\
\text { Emoções podem adotar e implementar para que a } \\
\text { demanda turística da região volte a crescer pós } \\
\text { pandemia? }\end{array}$ & $\begin{array}{l}\text { (Santos \& Ribeiro, 2016; Vieira, } \\
\text { Hoffmann \& Alberton, 2018; } \\
\text { Aguiar \& Melo, 2020; Baggio, } \\
\text { 2020; Menegaki, 2020; Oliveira \& } \\
\text { Arantes, 2020; Sheresheva, 2020) }\end{array}$ \\
\hline
\end{tabular}

Fonte: Elaborado pelos autores.

As entrevistas foram enviadas para os gestores das Empresas de Passeio (Receptivos) do setor do Turismo do destino da Rota das Emoções (Quadro 2). É importante salientar que 
Ribeiro, H. C. M., \& Moreira, A. A. A. P. (2021, maio/ago.). COVID-19: efeitos e implicações ocorridos no turismo da rota das emoções localizada no nordeste do Brasil

foram escolhidas três empresas de passeio, sendo que o critério para seleciona-las foi o seu respectivo destaque ao ser pesquisada no google utilizando o seguinte string de busca: Empresa de passeios no Ceará (Empresa A), Maranhão (Empresa C) e Piauí (Empresa B) e pela sua avalição positiva por parte dos clientes na plataforma de busca.

Em relação aos Receptivos, são empresas que trabalham com passeios e traslados terrestres dentre o estado de origem, podendo atender toda a Rota das Emoções caso exista uma demanda e a empresa detenha de transporte ou contrate o serviço de parceiros. Ex.: A Empresa A realiza traslados de Fortaleza (CE) para Jericoacoara e passeios pelas praias em todo o Ceará. A Empresa B realiza traslados de Parnaíba (PI) para Teresina (PI) e realiza passeios no Delta do Parnaíba e em todo o Estado do Piauí. A Empresa C realiza passeios em Barreirinhas (MA), Caburé (MA), Atins (MA) e traslados dentro de Barreirinhas (MA) e regiões vizinhas, são os chamados transfers.

No que tange aos respondentes, justifica-se enviar as entrevistas para os gestores, em virtude de cada um destes representar o alto executivo de cada empresa ora investigada, e, portanto, serem conhecedores de todas as especificidades e particularidades de suas respectivas empresas do ramo do turismo, essencial assim para se conseguir responder e alcançar a questão e o objetivo deste estudo concomitantemente. Ou seja, para cada empresa de passeio, foi entrevistado um alto executivo, totalizando três. E conforme o autor Rey (2005), o que importa na pesquisa de estudo de caso, não é o número de entrevistados, mas sim a seleção de pessoaschave, as quais, pelo detalhe de seus respectivos depoimentos, informações e conhecimentos acerca do fenômeno estudado, permitem ao pesquisadores um melhor entendimento e compreensão mais ampla do mesmo (Barreto \& Paula, 2014).

Quadro 2 - Entrevistados

\begin{tabular}{|c|c|c|c|c|c|}
\hline Entrevistados & Empresas & Gênero & Cargo & Função & $\begin{array}{c}\text { Duração da } \\
\text { Entrevista }\end{array}$ \\
\hline E1 & A & Feminino & Proprietária & $\begin{array}{c}\text { Desenvolver o } \\
\text { planejamento estratégico da } \\
\text { organização }\end{array}$ & $52 \mathrm{~min}$ \\
\hline E2 & B & Masculino & $\begin{array}{c}\text { Gerente } \\
\text { Administrativo e } \\
\text { Financeiro }\end{array}$ & $\begin{array}{c}\text { Gerenciar os setores } \\
\text { administrativo e financeiro } \\
\text { da organização }\end{array}$ & $34 \mathrm{~min} 9 \mathrm{~s}$ \\
\hline E3 & C & Masculino & $\begin{array}{c}\text { Proprietário } \\
\text { Desenvolver o }\end{array}$ & $\begin{array}{c}\text { Dlanejamento estratégico da } \\
\text { organização }\end{array}$ & \\
\hline \multicolumn{2}{|r|}{ As entrevistas se deram no período de 21 dias, iniciando em 10/06/2020 e finalizando em 01/07/2020. } \\
\hline
\end{tabular}

Fonte: Elaborado pelos autores. 
Ribeiro, H. C. M., \& Moreira, A. A. A. P. (2021, maio/ago.). COVID-19: efeitos e implicações ocorridos no turismo da rota das emoções localizada no nordeste do Brasil

Para a realização das entrevistas, foram consideradas quatro etapas: (i) o primeiro passo foi a realização de uma pesquisa no google utilizando a seguinte string de busca: Empresa de passeios no Ceará, Piauí e Maranhão. Após encontrar a empresa de maior destaque no ramo com as melhores avaliações foi feito o contato inicial via telefonema. Ao saber do interesse da empresa para colaborar com a pesquisa foi enviado um e-mail e uma mensagem padrão no WhatsApp corporativo da organização falando da pesquisa e seu objetivo geral; (ii) o segundo passo foi marcar a entrevista de acordo com a disponibilidade dos gestores responsáveis; (iii) o terceiro passo foi à realização da entrevista que se deu via telefonema utilizando dois celulares e um computador, de um celular foi feito a ligação, do outro foi feita a gravação e o computador era o suporte que continha o roteiro de entrevista (Quadro 1); (iv) e o quarto e último passo diz respeito às transcrições das entrevistas que foram realizadas utilizando o celular da gravação e um computador.

Para a pesquisa documental utilizou-se informações secundárias dos sites das empresas objeto de estudo (Karim, Haque \& Anis, 2020). Foram selecionadas estas empresas no destino turístico das Rota das Emoções: Jericoacoara (CE), Parnaíba (PI) e Barreirinhas (MA) (Costa, Nascimento, Hoffmann \& Silva, 2017). Categorizou-se os documentos por empresa assim: Documentos da Empresa $\mathrm{A}=$ DocsEmpA. Documentos da Empresa $\mathrm{B}=$ DocsEmpB. Documentos da Empresa $\mathrm{C}=$ DocsEmpC.

E a observação não participante para este estudo será feita mediante a visualização da dinâmica das entrevistas, ocorrendo concomitantemente algumas anotações, sem causar interferência significativa nas mesmas (Freitas \& Freitas, 2013). Ressalva-se que, devido o COVID-19 e, consequentemente ao distanciamento social, as entrevistas foram realizadas por meio remoto (Mercado, 2016), com a anuência do entrevistado respeitando para isso sua agenda de trabalho.

\subsection{Procedimentos de análise de dados}

Como dito anteriormente, a estratégia metodológica para esta pesquisa foi a do estudo de caso múltiplo descritivo, no qual as informações foram consolidadas e analisadas por meio da triangulação de dados oriundos das entrevistas, documentos e observações não participantes (Munck, Munck \& Souza, 2011). E a triangulação dos dados mitiga as inconsistências e contradições de um determinado estudo, colaborando com a validade das informações analisadas (Paiva Júnior, Leão \& Mello, 2011). Para aperfeiçoar a análise dos casos, além da triangulação dos dados, utilizou-se da Análise intercasos baseado no estudo de Miles e 
Ribeiro, H. C. M., \& Moreira, A. A. A. P. (2021, maio/ago.). COVID-19: efeitos e implicações ocorridos no turismo da rota das emoções localizada no nordeste do Brasil

Huberman (1994). Foi feita uma análise intercasos, onde foi realizada uma análise comparando os casos uns com os outros (Ribeiro, 2014).

\section{Análise e discussão dos resultados}

Essa seção abordará a análise e as discussões dos resultados subdivididas em 11 subseções.

\subsection{Entendimento sobre o COVID-19}

O Quadro 3 realça o entendimento dos entrevistados sobre o COVID-19.

\section{Quadro 3 - Entendimento sobre o COVID-19}

\begin{tabular}{|c|c|c|}
\hline Empresa A & Empresa B & Empresa C \\
\hline $\begin{array}{l}\text { "Algo invisível que veio para } \\
\text { desestruturar mundialmente } \\
\text { todos os seguimentos que existe, } \\
\text { a família, as empresas, o lado } \\
\text { pessoal de todos. Algo que a } \\
\text { gente não sabe como surgiu, mas } \\
\text { que veio com uma força muito } \\
\text { grande de destruição da } \\
\text { humanidade. Acabou tornando a } \\
\text { humanidade refém dele em todos } \\
\text { os aspectos e isso tem causado } \\
\text { grande prejuízo em todas as áreas } \\
\text { da vida humana" (E1). }\end{array}$ & $\begin{array}{l}\text { "O COVID-19 é um vírus que } \\
\text { está no mundo inteiro gerando } \\
\text { inúmeros impactos, é uma coisa } \\
\text { invisível que não sabemos onde } \\
\text { está e estamos refém dele" (E2). }\end{array}$ & $\begin{array}{l}\text { "Um vírus terrível, uma tragédia, } \\
\text { algo que prejudicou todo mundo, } \\
\text { inclusive o setor do turismo que } \\
\text { foi o primeiro a cair e será o } \\
\text { último a se levantar" (E3). }\end{array}$ \\
\hline
\end{tabular}

Fonte: Dados da pesquisa.

Lima et al. (2020) conceitua o COVID-19 como sendo uma doença respiratória aguda grave, considerada uma pandemia (Gossling, Scott \& Hall, 2020) que até o presente momento não existe medicamento para tratar e a principal estratégia para tentar conter o avanço deste vírus é o isolamento social (Manchein et al., 2020). Tais afirmações vão ao encontro, de maneira similar ao que os respondestes enfatizaram sobre o COVID-19, sobre o entrevistado E2 e o E3 os quais realçam a palavra vírus como descrição do COVID-19. De maneira geral, o COVID19 traz muitas dúvidas e medos na sociedade e a forma de descrevê-lo pode ser às vezes dificultada pela falta de informação do que é realmente o COVID-19, tornando-o impreciso, invisível e destrutivo como o entrevistado E1 colocou em relevo. 
Ribeiro, H. C. M., \& Moreira, A. A. A. P. (2021, maio/ago.). COVID-19: efeitos e implicações ocorridos no turismo da rota das emoções localizada no nordeste do Brasil

\subsection{Distanciamento social como estratégia para a pandemia}

O Quadro 4 enfoca sobre o distanciamento social como estratégia para o COVID-19.

Quadro 4 - Distanciamento social como estratégia para a pandemia

\begin{tabular}{|c|c|c|}
\hline Empresa A & Empresa B & Empresa C \\
\hline $\begin{array}{l}\text { "Eu acredito que o } \\
\text { distanciamento social é } \\
\text { importante sim, existem estudos } \\
\text { que comprovam isso } \\
\text { cientificamente uma vez que a } \\
\text { forma de contagio é a o contato } \\
\text { humano, então assim, é de } \\
\text { fundamental importância que } \\
\text { aconteça o isolamento social com } \\
\text { responsabilidade, mas o que que } \\
\text { acontece, existem pessoas que } \\
\text { estão cumprindo e outras não e a } \\
\text { forma como foi direcionado no } \\
\text { nosso país não foi muito eficaz } \\
\text { como foi colocado, porque por } \\
\text { trás desse isolamento social } \\
\text { existem inúmeros fatores que } \\
\text { impactam o desenvolvimento } \\
\text { humano e que não estão sendo } \\
\text { amparadas. As questões } \\
\text { psicológicas serão um grande } \\
\text { problema do futuro, pois } \\
\text { provocaram outras doenças por } \\
\text { conta do isolamento desordenado } \\
\text { imposto no nosso país, falta de } \\
\text { organização, condução e } \\
\text { preparo" (E1). }\end{array}$ & $\begin{array}{l}\text { "O isolamento social é uma } \\
\text { excelente estratégia, é mais eficaz } \\
\text { segundo estudos científicos, só } \\
\text { que a forma como ele está sendo } \\
\text { conduzida no nosso país não está } \\
\text { gerando resultados positivos para } \\
\text { ninguém, em especial para a } \\
\text { indústria do turismo. Ele só existe } \\
\text { na teoria porque na prática estão } \\
\text { existindo inúmeras } \\
\text { aglomerações, não existe uma } \\
\text { fiscalização efetiva" (E2). }\end{array}$ & $\begin{array}{l}\text { "O distanciamento é uma boa } \\
\text { estratégia, mas a meu ver no } \\
\text { nosso país foi mal conduzido e os } \\
\text { problemas só estão sendo } \\
\text { passados para frente. O Brasil } \\
\text { justificou o distanciamento social } \\
\text { como uma forma de preparar os } \\
\text { estados com estrutura para conter } \\
\text { o vírus, mas a gente sabe que não } \\
\text { é isso que está sendo feito, não } \\
\text { existe uma fiscalização e é um } \\
\text { falso distanciamento. Algumas } \\
\text { cidades fizeram o que deveria ser } \\
\text { feito e muitas outras não, como é } \\
\text { o caso de Parnaíba-PI não tem } \\
\text { teste, não tem planejamento, é } \\
\text { como se nada estivesse } \\
\text { acontecendo" (E3). }\end{array}$ \\
\hline
\end{tabular}

Fonte: Dados da pesquisa.

Bezerra et al. (2020) apresentaram resultados da pesquisa de opinião realizada no Brasil sobre a percepção do isolamento social durante a pandemia de COVID-19. Concluíram que a maior parte da sociedade brasileira acredita que se trata da medida/estratégia de controle mais indicada para o enfrentamento do COVID-19. Tal afirmação é corroborada nos estudos de: Gossling, Scott e Hall (2020), Kuwahara, Kuroda e Fukuda (2020), Manchein et al. (2020), Sheresheva (2020).

Observando o Quadro 4, o que os respondentes colocam sobre o isolamento social como estratégia eficaz para conter a disseminação do COVID-19 é válida, indo ao encontro aos autores contemplados nesta seção, porém, de maneira integral os respondentes afirmam que o isolamento social em nosso país não está sendo realizado de maneira satisfatória, em decorrência de variáveis, econômicas, políticas e ou sociais (Farzanegan et al., 2020) que de 
Ribeiro, H. C. M., \& Moreira, A. A. A. P. (2021, maio/ago.). COVID-19: efeitos e implicações ocorridos no turismo da rota das emoções localizada no nordeste do Brasil

certa forma prejudicam o entendimento e a compreensão das pessoas no que concerne a respeitar o distanciamento social e, consequentemente o isolamento social.

Em suma, as atividades turísticas nos três estados que compõem a rota das emoções foram cessadas no mesmo período, no final do mês de março de 2020, entretanto as ações que foram tomadas em cada estado se apresentaram distintas, cada gestor público ditou suas regras, assim como os gestores de todo o país, fazendo com que a ações em prol desse isolamento não fossem conjuntas o que prejudicou o setor em questão demasiadamente, tornando insatisfação por parte dos gestores de empresas da indústria do turismo, tal afirmação é percebida na fala dos três entrevistados gerando a análise e discussão da próxima seção.

\subsection{Implicações do isolamento social para o Turismo}

O Quadro 5 aborda as implicações do isolamento social para o setor do turismo.

\begin{tabular}{|c|c|c|}
\hline Empresa A & Empresa B & Empresa C \\
\hline $\begin{array}{l}\text { "Os impactos no turismo foram } \\
\text { grotescos e a forma como o } \\
\text { isolamento social foi conduzido } \\
\text { prejudicou ainda mais o setor, } \\
\text { porque na medida em que foram } \\
\text { surgindo os casos, cada estado } \\
\text { agiu de uma forma, foi fechado } \\
\text { tudo sem comunicação o trade } \\
\text { turístico ficou cambaleando, } \\
\text { desnorteado, sem saber o que } \\
\text { fazer, mais ainda... Pessoas que } \\
\text { estavam em viagem foram } \\
\text { pegues de surpresa e causou um } \\
\text { pânico inicial os turistas e as } \\
\text { empresas por ambos não saberem } \\
\text { como reagir diante disso. Um } \\
\text { prejuízo gigantesco foi gerado, } \\
\text { especialmente econômico. É } \\
\text { como se fosse uma cadeia em } \\
\text { degradação no contexto dessa } \\
\text { pandemia" (E1). }\end{array}$ & $\begin{array}{l}\text { "Os impactos no turismo foram } \\
\text { sem precedentes, o turismo por } \\
\text { ser uma atividade de lazer foi o } \\
\text { primeiro a parar e o último a } \\
\text { voltar, estamos parados a mais de } \\
90 \text { dias com faturamento zero, os } \\
\text { prejuízos econômicos são } \\
\text { desastrosos" (E2). }\end{array}$ & $\begin{array}{l}\text { "Os impactos foram muitos, } \\
\text { começou com o fechamento do } \\
\text { aéreo, depois as grandes } \\
\text { agências, as ações da CVC } \\
\text { despencaram na bolsa, muitas } \\
\text { demissões e pessoas passando } \\
\text { por necessidade, Delta do } \\
\text { Parnaíba totalmente fechado. Os } \\
\text { menores que dependem do } \\
\text { turismo local estão sofrendo } \\
\text { muito" (E3). }\end{array}$ \\
\hline
\end{tabular}

Fonte: Dados da pesquisa.

Verificando as respostas dos entrevistados, constata-se de maneira unanime que o isolamento social em virtude da pandemia foi negativo em termos econômico e financeiro para o turismo da região. As empresas estão a mais de 90 dias sem realizar seus serviços, ou seja, são mais de três meses sem operar na Rota das Emoções impactando em demissões e prejuízos ainda incalculáveis e sem precedentes. O E3 relata dos impactos ocasionados de maior vulto 
Ribeiro, H. C. M., \& Moreira, A. A. A. P. (2021, maio/ago.). COVID-19: efeitos e implicações ocorridos no turismo da rota das emoções localizada no nordeste do Brasil

com empresas menores, como demissões, evidenciando que esses impactos acabam fragilizando a relação empresa e comunidade, expondo a falta de ações que emerjam da responsabilidade social das empresas envolvidas no trade turístico. Tais afirmativas são corroboradas por Carbone (2020) que enfatiza que a pandemia do COVID-19 é provavelmente o stress test mais difícil e desafiador para todo o setor do turismo global. Com isso, localidades turísticas internacionais deverão se adaptar as mudanças sociais e econômicas (Gossling, Scott \& Hall, 2020; Hall, Scott \& Gössling, 2020). De maneira geral, é constatável que o isolamento social impactou as empresas do setor do turísmo (Gossling, Scott \& Hall, 2020; Sheresheva, 2020), gerando implicações econômicas sem precedentes no mundo (Senhoras \& Nascimento, 2020).

\subsection{Impactos da pandemia no turismo no Brasil}

O Quadro 6 evidencia os impactos do COVID-19 no setor do turismo no Brasil.

Quadro 6 - Impactos da pandemia no turismo no Brasil

\begin{tabular}{|c|c|c|}
\hline Empresa A & Empresa B & Empresa C \\
\hline $\begin{array}{l}\text { "Sim. Com toda certeza, primeiro } \\
\text { porque a questão econômica é } \\
\text { muito grave, empresas faliram, } \\
\text { pessoais perderam seus } \\
\text { empregos, os que trabalharam de } \\
\text { forma informal estão sem se } \\
\text { movimentar. Acaba que teve uma } \\
\text { quebra gigantesca da economia, } \\
\text { as pessoas continuam tendo suas } \\
\text { contas a pagar e não tem recursos } \\
\text { suficientes, então a última opção } \\
\text { para muitos será o viajar. } \\
\text { Qualquer destino turístico no } \\
\text { Brasil é caro. Segundo as pessoas } \\
\text { ainda vão ficar receosas, as } \\
\text { pessoas vão querer sair, mas não } \\
\text { tem dinheiro suficiente e terão } \\
\text { medo. A classe do turismo terá de } \\
\text { se unir para criar estratégias para } \\
\text { atrair esse público. Quando tudo } \\
\text { passar e puder viajar e quem vai } \\
\text { ter recurso é a classe média alta } \\
\text { que vai optar por destinos } \\
\text { internacionais" (E1). }\end{array}$ & $\begin{array}{l}\text { "Já estamos sofrendo, o impacto } \\
\text { é grande, o estrago é gigante e } \\
\text { nós esperamos que o turismo } \\
\text { doméstico se fortaleça visto que } \\
\text { já perdemos a alta temporada } \\
\text { com turistas internacionais. O } \\
\text { que nos resta é aguardar pelos } \\
\text { turistas da classe média alta de } \\
\text { estados vizinhos para que se } \\
\text { fortaleça o turismo das pequenas } \\
\text { regiões" (E2). }\end{array}$ & $\begin{array}{l}\text { "Já estamos sofrendo, e o Brasil } \\
\text { ainda vai sofrer muito mais } \\
\text { porque não temos o habito do } \\
\text { turismo doméstico, nosso público } \\
\text { é mais estrangeiro, então } \\
\text { precisamos repensar muito o } \\
\text { nosso turismo a partir de agora, } \\
\text { com o covid-19, porque já } \\
\text { estamos parados a muito tempo e } \\
\text { não tem empresa que se aguente } \\
\text { assim. Até a gente ter a vacina } \\
\text { precisamos agir com calma"(E3). }\end{array}$ \\
\hline
\end{tabular}

Fonte: Dados da pesquisa.

Observando as respostas dos entrevistados evidenciadas no Quadro 6, sobre os impactos do COVID-19 no turismo no Brasil, todos foram unanimes em afirmar que sim, os impactos da pandemia para o setor são devastadores. Com isso, os entrevistados consideram esse um ano 
Ribeiro, H. C. M., \& Moreira, A. A. A. P. (2021, maio/ago.). COVID-19: efeitos e implicações ocorridos no turismo da rota das emoções localizada no nordeste do Brasil

perdido para a classe visto que as incertezas são inúmeras. E que o turismo sofreu um grande prejuízo, e que demorará para que a região volte a tornar-se viável para todas as camadas da sociedade, sobretudo, para a classe média alta e ou os turistas estrangeiros, que são, de acordo com os respondentes os principais aportes financeiros e econômicos para as empresas de passeio investigadas dos três estados objeto de estudo da Rota das Emoções.

Posto isto, fica evidente e notório que a pandemia impactará sobretudo em países emergentes e turísticos como é o caso do Brasil, em especial na região Nordeste a qual a Rota das Emoções se localiza (Costa, Nascimento, Hoffmann \& Silva, 2017; Silva, Hoffmann \& Costa, 2020). Deste modo, países como estes precisam aprender de maneira coletiva a vencer essa tragédia do COVID-19, que impactou, impacta e impactará ainda mais o contexto do setor do turismo dos países, inviabilizando fortemente a economia local destes países (Carbone, 2020; Menegaki, 2020; Oliveira \& Arantes, 2020; Gossling, Scott \& Hall, 2020; Sayfullaev, 2020; Sheresheva, 2020), inclusive do Brasil (Aguiar \& Melo, 2020).

\subsection{Crescimento do setor do turismo antes e pós-pandemia}

O Quadro 7 contempla sobre o crescimento do setor do turismo antes e pós pandemia.

Quadro 7 - Crescimento do setor do turismo antes e pós pandemia

\begin{tabular}{|c|c|c|}
\hline Empresa A & Empresa B & Empresa C \\
\hline $\begin{array}{l}\text { "As perspectivas antes da } \\
\text { pandemia eram as melhores, } \\
\text { estávamos apostando tudo esse } \\
\text { ano, o ano de } 2019 \text { não foi tão } \\
\text { ruim, mas a gente iniciou } 2020 \\
\text { cheio de planos por achar ser } \\
\text { melhor e a gente apostava porque } \\
\text { a gente teve um inverno muito } \\
\text { bom, nosso estado estava com os } \\
\text { principais destinos turísticos } \\
\text { muito bonitos, as praias e as } \\
\text { lagoas, tudo muito limpo. } \\
\text { Chegou janeiro a gente disse, será } \\
\text { um ano gigante porque a busca } \\
\text { estava muito grande para o } \\
\text { primeiro semestre. Infelizmente } \\
\text { devido a isso que aconteceu, } \\
\text { encerramos nossas atividades em } \\
\text { 20 de março e acabou que } \\
\text { estamos parados. Estamos } \\
\text { trabalhando para que as pessoas } \\
\text { remarquem suas viagens, mas } \\
\text { existe muita procura para } \\
\text { cancelamento devido à questão } \\
\text { econômica. Nesses últimos dias }\end{array}$ & $\begin{array}{l}\text { "Para esse ano tínhamos uma } \\
\text { expectativa de crescimento } \\
\text { econômico muito grande, janeiro } \\
\text { já tinha mostrado que seria } \\
\text { melhor do que o ano passado, } \\
\text { nossa região com muita chuva } \\
\text { está linda, mas com tudo que } \\
\text { aconteceu e enquanto não } \\
\text { tivermos uma vacina para acabar } \\
\text { com esse vírus só podemos fazer } \\
\text { projeções de sobrevivência para } \\
\text { esse ano e o pós-pandemia só virá } \\
\text { com a vacina, antes disso é } \\
\text { sobreviver com esse novo } \\
\text { normal" (E2). }\end{array}$ & $\begin{array}{l}\text { "Pré-Pandemia tínhamos uma } \\
\text { excelente expectativa, o Brasil } \\
\text { estava fechando parceria com } \\
\text { novas agências assim teríamos } \\
\text { muitos novos turistas, além dos } \\
\text { que já estavam procurando e } \\
\text { fechando pacotes, para o pós- } \\
\text { pandemia esperamos que tudo } \\
\text { melhore, sabemos que não vai ser } \\
\text { fácil, teremos de adotar novos } \\
\text { hábitos, o home office vai ser } \\
\text { oficializado com mais } \\
\text { intensidade, contudo acreditamos } \\
\text { que tudo vai ficar bem" (E3). }\end{array}$ \\
\hline
\end{tabular}




\begin{tabular}{|l|l|l|}
\hline estamos trabalhando um & & \\
diferencial atrativo para o nosso & & \\
turista, matemos reuniões & & \\
sistemáticas entre a classe para & & \\
pensar de que forma nós podemos & & \\
trazer esse cliente até nós nesse & & \\
pós-pandemia, sabemos que & & \\
vamos ter que trabalhar valores & & \\
atrativos e protocolos de & & \\
segurança" (E1).
\end{tabular}

Fonte: Dados da pesquisa.

Averiguando as respostas dos três entrevistados, todos afirmam que antes da pandemia surgir às expectativas para o turismo da Rota das Emoções em seus respectivos estados era muito boas, com crescimento da procura de viagens, e, consequentemente com o crescimento econômico, tudo apontava para um ano de grandes resultados, entretanto, em meados do final de março tudo mudou, pedidos para cancelamento de viagens surgiram, diminuição drásticas das viagens para a região, impactando diretamente na queda do turismo da Rota das Emoções nos três estados investigados. E, para pós-pandemia, o que fazer? Tentar implementar estratégias diferenciadas, sobreviver e torcer para que a vacina venha o mais rápido possível, pois só assim, de acordo com os respondentes é que o turismo da Rota das Emoções voltará, de maneira pausada e segura, a aflorar e alargar novamente.

No estudo de Romão (2020) o qual verifica o impacto do COVID-19 o turismo receptivo em Portugal, o autor constatou ser necessário repor os níveis de confiança dos visitantes e dos agentes turísticos internacionais no destino turismo. Ele conclui afirmando que também é necessário que Governo, Agentes Turísticos e a sociedade em geral possam saber viver num “novo normal”. E para os autores Figueira et al. (2020) a retomada na normalidade do turismo pós pandemia, só será possível com o processo de ensino-aprendizagem do turismo alicerçada pela educação superior.

\subsection{Projeção de demanda turística do setor antes e pós-pandemia}

O Quadro 8 visualiza a projeção de demanda do setor do turismo antes e pós COVID19. 
Ribeiro, H. C. M., \& Moreira, A. A. A. P. (2021, maio/ago.). COVID-19: efeitos e implicações ocorridos no turismo da rota das emoções localizada no nordeste do Brasil

Quadro 8 - Projeção de demanda turística do setor antes e pós pandemia

\begin{tabular}{|c|c|c|}
\hline Empresa A & Empresa B & Empresa C \\
\hline $\begin{array}{l}\text { "Existiam muitas demandas para } \\
2020 \text {, tínhamos uma busca } \\
\text { satisfatória desde outubro do ano } \\
\text { passado para o ano todo, a alta } \\
\text { estação estava bem procurada, } \\
\text { nosso maior público estava } \\
\text { concentrado entre julho e } \\
\text { outubro, o Ceará é invadido pelos } \\
\text { europeus que procuram nossas } \\
\text { áreas "calhentes (quentes)", } \\
\text { tínhamos muitas demandas, } \\
\text { contratos foram firmados e ai } \\
\text { quando surgiu à pandemia a } \\
\text { maioria dos clientes pediram } \\
\text { cancelamento e outra parte } \\
\text { adiamento. Para pós-pandemia } \\
\text { uma busca tímida está surgindo, } \\
\text { as pessoas estão curiosas para } \\
\text { saber como está a questão do } \\
\text { funcionamento e as aberturas de } \\
\text { cada estado da rota das emoções, } \\
\text { mas até o momento só } \\
\text { informações, nada fechado até } \\
\text { porque não temos previsão de } \\
\text { quando será aberto nada, o Ceará } \\
\text { inteiro está parado devido a } \\
\text { grande quantidade de casos" } \\
\text { (E1). }\end{array}$ & $\begin{array}{l}\text { "Existia muita demanda para esse } \\
\text { ano, nossa alta estava bombando, } \\
\text { mas hoje existem apenas curiosos } \\
\text { querendo saber do } \\
\text { funcionamento dos serviços, se } \\
\text { os estados da rota estão abrindo e } \\
\text { que medidas estão adotando, mas } \\
\text { nenhum pacote de passeio sendo } \\
\text { fechado. No momento apenas } \\
\text { cancelamento e adiamento, mas } \\
\text { sem nada concretizado para o } \\
\text { futuro. Para a gente vender } \\
\text { precisamos da abertura do parque } \\
\text { nacional e no momento tudo está } \\
\text { fechado, o que sabemos é que } \\
\text { muita coisa mudou e vai } \\
\text { continuar mudando, no protocolo } \\
\text { de segurança e no valor do } \\
\text { serviço" (E2). }\end{array}$ & $\begin{array}{l}\text { "Para o pré-pandemia tinha uma } \\
\text { demanda gigante, estávamos } \\
\text { enxugando processos e fazendo } \\
\text { uma análise com o ano passado } \\
\text { estávamos batendo, nossa alta } \\
\text { estava quase fechada, ou seja, } \\
\text { superior ao passado e então à } \\
\text { gente fechou em } 20 \text { de março } \\
\text { fechamos e desde então só } \\
\text { cancelamento e adiamento. } \\
\text { Estamos com reservas para } \\
\text { agosto, mas não sabemos como } \\
\text { tudo vai funcionar. Para o pós- } \\
\text { pandemia existe uma busca para } \\
\text { fim do ano e ano que vem, } \\
\text { estamos fechando passeios e } \\
\text { campanhas" (E3). }\end{array}$ \\
\hline
\end{tabular}

Fonte: Dados da pesquisa.

Constata-se que empresas alteram suas estratégias e projeções por sofrerem influências externas e internas (Soares \& Mazon, 2020). Posto isto, observa-se que para todos os entrevistas, a demanda antes da pandemia era muito grande, muitas procuras para viagem, pois a Rota das Emoções é um dos principais pontos turísticos do Nordeste do Brasil (Costa, Nascimento, Hoffmann \& Silva, 2017; Silva, Hoffmann \& Costa, 2020), contudo, com a chegada do COVID-19, de acordo com os gestores, houve muitos cancelamentos e ou adiamentos de viagem e procura. E, atualmente, existem apenas curiosos. Para o entrevistado E1, não existe expectativa de abertura devido aos grandes casos da pandemia no Ceará. Para o entrevistado E2 é preciso ter protocolos de segurança para voltar a ter procura no destino turístico local, e para o E3 afirma que existe procura, porém bem tímida, mas para o fim do ano de 2020.

Isso mostra as dificuldades de planejamento turístico para o pós-pandemia, devido à instabilidade social, econômica, o medo da sociedade as incertezas que norteiam a população, impactando diretamente no processo de mitigação e ou até mesmo esvaziamento da busca do 
Ribeiro, H. C. M., \& Moreira, A. A. A. P. (2021, maio/ago.). COVID-19: efeitos e implicações ocorridos no turismo da rota das emoções localizada no nordeste do Brasil

turismo da Rota das Emoções por parte dos turistas locais, e, sobretudo dos turistas internacionais, porém, completamente compreensível devido a esta pandemia, sem precedentes no mundo que assola a humanidade nestes tempos, tornando-os bem difíceis para todos.

Porém é importante salientar que, devido ao alto grau de incidência do COVID-19 no Brasil (Bezerra et al., 2020), impacta na vinda de turistas estrangeiros, fronteiras fechadas entre países, inviabilizando a chegada de novos turistas no país, impactando diretamente na economia local, em especial na Rota das Emoções objeto de estudo. Ou seja, políticas erradas para controle do COVID-19 influencia na maior disseminação da pandemia, atrasando com isso o retorno das atividades turísticas e normalizando-as, ao contrário de países, como Espanha, Itália, Alemanha, Portugal que se preocuparam em controlar a pandemia e, com isso, fazer projeções e prospecções mais reais no que se refere a retomada das atividades com parcimônia, segurança, controle, e respeito a sociedade (Farzanegan et al., 2020; Romão, 2020; Gossling, Scott \& Hall, 2020).

\subsection{Prospecção de demanda turística do setor antes e pós-pandemia}

19.

O Quadro 9 vislumbra a prospecção de demanda do setor turístico antes e pós COVID-

Quadro 9 - Prospecção de demanda turística do setor antes e pós pandemia

\begin{tabular}{|c|c|c|}
\hline Empresa A & Empresa B & Empresa C \\
\hline $\begin{array}{l}\text { "Como eu falei em umas das } \\
\text { questões anteriores tínhamos } \\
\text { uma demanda grande, todo nosso } \\
\text { marketing estava focado em } \\
\text { prospectar novos clientes e nós } \\
\text { atávamos conseguindo bons } \\
\text { resultados, mas como tudo que } \\
\text { aconteceu tudo mudou e agora } \\
\text { para o pós- pandemia estamos } \\
\text { trabalhando unidos, através de } \\
\text { reuniões com a classe estamos } \\
\text { cobrando apoio do governo para } \\
\text { melhorar essa situação na qual } \\
\text { nos encontramos" (E1). }\end{array}$ & $\begin{array}{l}\text { "Nós tínhamos uma prospecção } \\
\text { de demanda para o crescimento } \\
\text { turístico muito boa, existia uma } \\
\text { procura muito grande e nós } \\
\text { tínhamos/temos uma rede de } \\
\text { relacionamento com parceiros } \\
\text { muito eficiente, e para o pós- } \\
\text { pandemia pretendemos continuar } \\
\text { fortalezando essa relação } \\
\text { trabalhando a segurança do } \\
\text { cliente nesse trecho e mostrando } \\
\text { através do marketing" (E2). }\end{array}$ & $\begin{array}{l}\text { "Antes a gente trabalhava com } \\
\text { muitas campanhas para atrair } \\
\text { clientes e agora estamos } \\
\text { trabalhando mais ainda, isso está } \\
\text { surtindo muitos efeitos, é a posta } \\
\text { do marketing digital e } \\
\text { promoções" (E3). }\end{array}$ \\
\hline
\end{tabular}

Fonte: Dados da pesquisa;

A prospecção força os gestores a pensar no futuro, formulando situações, analisando decisões, possibilitando empreender estratégias competitivas (Ribeiro \& Forte, 2019). Posto isto, e lendo as respostas dos entrevistados no que concerne a prospecção de demanda do turismo antes e pós-pandemia, todos enfatizam o marketing como principal estratégia para se conseguir alavancar clientes e com isso, voltar a ter resultados no futuro. 
Ribeiro, H. C. M., \& Moreira, A. A. A. P. (2021, maio/ago.). COVID-19: efeitos e implicações ocorridos no turismo da rota das emoções localizada no nordeste do Brasil

Também enfatizaram (os respondentes) que antes da pandemia tinham prospectado boas demandas, porém, devido à pandemia tal fato foi prospectado foi irreal, tornando o cenário prospectado pessimista (Ribeiro \& Forte, 2019). O entrevistado E1 também enfatiza esperar do governo ajuda para conseguir melhorar a situação muito difícil que o setor do turismo na região local se encontra, como um todo na Rota das Emoções. Soares e Mazon (2020) incorpora e vislumbra o governo como um dos principais stakeholders com papel relevante neste momento para se conseguir manter a sobrevivência das empresas.

As empresas entrevistadas têm uma forte presença nas mídias sociais, elas são seu principal aliado no lançamento das estratégias de marketing, por isso continuam apostando nelas. Ao pesquisar pelas organizações encontra-se facilmente a divulgação de suas estratégias em seus sites, e perfis coorporativos. "Em busca de transfer em veículo $4 \times 4$, com toda a segurança e conforto? A empresa (A) tem! Vamos levar você aos mais lindos e badalados destinos turísticos do Ceará" (DocsEmpA, 2020).

“Atendemos à legislação aplicável ao nosso negócio, principalmente no que se refere ao meio ambiente e a segurança. Buscamos sempre a melhoria contínua de serviços, processos e pessoas" (DocsEmpB, 2020)." Qualidade é nossa marca! Por isso contamos com uma equipe experiente e devidamente treinada para oferecer um atendimento especializado, para fazer de sua viagem ou passeio uma experiência única e inesquecível” (DocsEmpC, 2020).

\subsection{Empresas do turismo com maior desgaste com a pandemia e pós COVID-19}

O Quadro 10 discorre sobre as empresas do turismo com maior desgaste em decorrência da pandemia e pós COVID-19. 
Ribeiro, H. C. M., \& Moreira, A. A. A. P. (2021, maio/ago.). COVID-19: efeitos e implicações ocorridos no turismo da rota das emoções localizada no nordeste do Brasil

Quadro 10 - Empresas do turismo com maior desgaste com a pandemia e pós COVID-19

\begin{tabular}{|c|c|c|}
\hline Empresa A & Empresa B & Empresa C \\
\hline $\begin{array}{l}\text { "Não existem um setor mais } \\
\text { afetado, todas foram afetadas e } \\
\text { todas estão intercaladas, o setor } \\
\text { da hotelaria não funciona sem o } \\
\text { transporte, a gastronomia local } \\
\text { não funciona sem o turista e para } \\
\text { ele chegar tem que ter o } \\
\text { transporte e a hospedagem e os } \\
\text { passeios tem que acontecer para } \\
\text { que muitas vezes o cliente chegue } \\
\text { ao pequeno restaurante ou } \\
\text { barraca local, para o cliente } \\
\text { chegar no nosso estado ele vem } \\
\text { pelo aéreo, dentro do estado ele } \\
\text { se desloca através do terrestre, } \\
\text { então todo mundo é importante } \\
\text { para o trecho, somos uma cadeia } \\
\text { intercalada e todos dependem uns } \\
\text { dos outros, as agências trabalham } \\
\text { o pacote completo está } \\
\text { gravemente afetada, então todos } \\
\text { estão no mesmo barco na mesma } \\
\text { intensidade, o que vai existir são } \\
\text { empresas pequenas e empresas } \\
\text { grande e ambas estão muito } \\
\text { prejudicadas , quem tem a } \\
\text { pequena demitiu a metade e quem } \\
\text { tem a grande também. Muitas } \\
\text { pessoas ficaram desempregadas e } \\
\text { isso é muito triste e todos foram } \\
\text { gravemente afetados" (E1). }\end{array}$ & $\begin{array}{l}\text { "O receptivo (quem faz passeio) } \\
\text { é o setor mais afetado porque está } \\
\text { totalmente sem trabalhar, mas se } \\
\text { for analisar o todo, todas as } \\
\text { empresas do setor estão afetadas } \\
\text { completamente porque o turismo } \\
\text { é uma cadeia interligada, se não } \\
\text { tem cliente para andar de avião, } \\
\text { não tem para se hospedar e nem } \\
\text { para comer e beber nos bares e } \\
\text { restaurantes da região turística, } \\
\text { então esperamos que isso volte } \\
\text { mesmo que aos poucos, com uma } \\
\text { nova cara, novas ideais e temos } \\
\text { que trabalhar o cliente para ele se } \\
\text { sinta seguro na realização desses } \\
\text { serviços"(E2). }\end{array}$ & $\begin{array}{l}\text { "Em minha opinião, as } \\
\text { operadoras estão sendo as } \\
\text { primeiras afetadas, elas que tem o } \\
\text { trabalho de amarrar toda uma } \\
\text { logística de conseguir cliente fora } \\
\text { do Brasil, trazer para cá e passar } \\
\text { para os terceirizados, depois } \\
\text { delas toda a cadeia que faz parte } \\
\text { do turismo está sendo afetada. Lá } \\
\text { fechou primeiro, o cancelamento } \\
\text { começa de lá e vai afetando todos } \\
\text { os outros têm muita operadora } \\
\text { fechando. Nós ainda } \\
\text { conseguimos nos manter como } \\
\text { turismo doméstico local ainda } \\
\text { está em pé" (E3). }\end{array}$ \\
\hline
\end{tabular}

Fonte: Dados da pesquisa.

De maneira geral, todos os três respondentes concordam que todo o setor do turismo foi afetado de maneira drástica, em decorrência da pandemia (Coelho \& Mayer, 2020), pois o setor do turismo não só da região, mas de localidades turísticas, em especial da Rota das Emoções que é o objeto de estudo, são interligados, desde das companhias de viagem, operadoras, receptivos (empresas de passeio), hotéis (Vieira, Hoffmann \& Alberton, 2018; Volpi \& Paulino, 2019), todos foram impactados de alguma maneira de acordo com os entrevistas, uns mais, outros menos, mas de maneira macro todos por serem conectados estão sofrendo perdas por causa do COVID-19 (Romão, 2020; Sayfullaev, 2020).

Tal fato mostra que o desgaste do turismo por conta do COVID-19 é mais aflorado e contundente em países emergentes, como é o caso do Brasil, e com isso, estes terão que instruir- 
Ribeiro, H. C. M., \& Moreira, A. A. A. P. (2021, maio/ago.). COVID-19: efeitos e implicações ocorridos no turismo da rota das emoções localizada no nordeste do Brasil

se em uma rede de colaboração e interação mais densa para conseguir se recuperar com o mínimo de danos possíveis dessa tragédia global, minimizando efeitos e transformações em suas respectivas localidades turísticas (Carbone, 2020; Farzanegan, et al., 2020; Gossling, Scott \& Hall, 2020).

\subsection{Característica do destino turístico e sua influência na recuperação pós-pandemia}

O Quadro 11 enfatiza as características do destino turístico e seu impacto na recuperação pós COVID-19.

Quadro 11 - Característica do destino turístico e sua influência na recuperação pós pandemia

\begin{tabular}{|l|l|l|}
\hline \multicolumn{1}{|c|}{ Empresa A } & \multicolumn{1}{|c|}{ Empresa B } & \multicolumn{1}{c|}{ Empresa C } \\
\hline "Sim, com certeza. Primeiro pela & "Sim, com toda certeza, nossa & "Sim. Com toda certeza, eu acho \\
beleza natural, temos uma região & região é rica em belezas naturais, & que nossas belezas naturais \\
mundialmente admirada, o Ceará & sol e praia, uma diversidade de & continuaram chamando atenção e \\
tem as mais belas praias do & culturas, tem muito atrativo, são & passando tudo isso, quando o país \\
nordeste e segundo a questão do & três estados cada um com sua & voltar a crescer as coisas vão \\
clima tropical. Os europeus & diferença regional. É um produto & melhorar e mais investimentos \\
invadem nosso Nordeste, nosso & que vende por sí só, uma foto do & serão feitos. O Nordeste é \\
Ceará especialmente em Jeri, & destino visitado vale mais que mil & abençoado e chama atenção" \\
Preá e Cumbuco para o & palavras. A rota das emoções é & (E3). \\
campeonato mundial de kitesurf & completa e eu estou apostando & \\
único" (E1). & muito nisso na retomada" (E2). & \\
\hline
\end{tabular}

Fonte: Dados da pesquisa.

Ao considerar que um destino turístico vai muito além do que pode ser visto ou adquirido (Gomes, Gândara \& Ivars-Baidal, 2017), contempla-se as respostas dos entrevistados evidenciadas no Quadro 11, as quais concordam de maneira plena, ou seja, todos acordam que as características de cada destino turístico de seus respectivos estados que compõem a Rota das Emoções, CE, PI e MA são primordiais e essenciais para a retomada da normalidade pós pandemia. Tal afirmação é corroborada por Baggio (2020) ao conceber que as características estruturais de um determinado destino turístico são preponderantes e essenciais, uma vez que contribuem e impactam seu comportamento dinâmico.

A afirmação em questão também é corroborada e complementa por Caldeira (2013) a qual realça que a atratividade de um destino turístico pode ser vista como sendo constituída por recursos locais exclusivos, como é o caso dos destinos respectivos dos estados que compõe a Rota das Emoções. Também cabe mencionar os atributos culturais, recursos naturais, infraestrutura, serviços dentre outros. Posto isto, enfoca-se que o produto turístico pode ser analisado em termos de atração, estrutura e acessibilidade com a finalidade de descobrir a sua característica que o atrai (Caldeira, 2013). E a conexão entre destinos turísticos, como ocorre 
Ribeiro, H. C. M., \& Moreira, A. A. A. P. (2021, maio/ago.). COVID-19: efeitos e implicações ocorridos no turismo da rota das emoções localizada no nordeste do Brasil

na Rota das Emoções, cria vantagem competitiva para a região, influenciando com isso o seu crescimento fazendo surgir novos destinos turísticos (Santos \& Ribeiro, 2016).

\subsection{Rota das Emoções como cluster impacta na recuperação do setor pós-pandemia}

O Quadro 12 relata a Rota das Emoções como clusters e sua influência na recuperação do setor turístico pós pandemia.

Quadro 12 - Rota das Emoções como cluster impacta na recuperação do setor pós pandemia

\begin{tabular}{|c|c|c|}
\hline Empresa A & Empresa B & Empresa C \\
\hline $\begin{array}{l}\text { "Sim. Com toda certeza porque } \\
\text { não existe setor do turismo } \\
\text { isolado, um depende do outro, a } \\
\text { agência que vende e não tem } \\
\text { veículos vai precisar de um } \\
\text { fornecedor terceirizado, se ele } \\
\text { vende hospedagem então tem } \\
\text { hotel, ele vai em busca de um } \\
\text { hotel parceiro. O turismo é uma } \\
\text { forte engrenagem, que trabalha } \\
\text { em conjunto e estamos } \\
\text { trabalhando para unir forças e } \\
\text { buscar estratégias de marketing } \\
\text { para atrair da melhor forma esse } \\
\text { turista que deseja viajar a rota das } \\
\text { emoções, pois cada estado que } \\
\text { compõem essa rota apresenta sua } \\
\text { peculiaridade que faz com que o } \\
\text { cliente saia encantado e com uma } \\
\text { experiência diferenciada de cada } \\
\text { um"(E1). }\end{array}$ & $\begin{array}{l}\text { "Sim, porque uma empresa } \\
\text { depende da outra e juntas elas se } \\
\text { fortalecem. O turismo é como o } \\
\text { corpo humano, para tudo ficar } \\
\text { bem todos devem estar bem, e } \\
\text { estamos em um momento de } \\
\text { trabalhar em conjunto apesar das } \\
\text { individualidades empresariais" } \\
\text { (E2). }\end{array}$ & $\begin{array}{l}\text { "Sim, pois no pré-pandemia nós } \\
\text { já trabalhávamos com muito com } \\
\text { parcerias, é um turismo } \\
\text { amarrado, um depende do outro, } \\
\text { cada um faz o seu melhor e todos } \\
\text { continuaram se ajudando para } \\
\text { entregar o melhor da região para } \\
\text { o cliente" (E3). }\end{array}$ \\
\hline
\end{tabular}

Fonte: Dados da pesquisa.

Entende-se que os clusters turísticos são compostos por empresas numa mesma região geográfica que focam em fomentar sua competitividade e performance, e contribuindo e impactando no desenvolvimento regional da localidade (Sohn et al., 2017). Isto posto, e averiguando as respostas dos entrevistados no Quadro 12, observa-se a integralidade em concordar que os clusters das empresas de turismo que compõem a Rota das Emoções é essencial para desenvolver a região, pois, como entrevistados relataram, as parcerias, a colaboração, ou seja o network entre as empresas que fazem acontecer os pontos turísticos da rota em investigação, impactando positivamente na criação de valor, influenciando no crescimento, pois, como o respondente E1 evidenciou, não existe setor do turismo isolado, todos precisam de todos, como um organismo vivo, como bem observado pelo entrevistado E2, impactando em uma ajuda mútua como dito pelo E3. 
Ribeiro, H. C. M., \& Moreira, A. A. A. P. (2021, maio/ago.). COVID-19: efeitos e implicações ocorridos no turismo da rota das emoções localizada no nordeste do Brasil

Compreende-se com isso que um cluster apresenta características intrínsecas à globalização, integrando empresas com um objetivo comum (Mazaro \& Varzin, 2008), como se observa com as empresas que compõem a Rota das Emoções, e em especial, as empresas de passeio que é o foco deste estudo. Afirmações estas corroboradas por Santos, Ribeiro e Silveira (2018) e Melo, Monteiro e Brito (2018) que realçam em suas respectivas pesquisas que Jericoacoara e os Lençóis Maranhenses estão entre os principais clusters turísticos do Nordestes; e que o Delta do Parnaíba em decorrência de seu crescimento robusto e alargado nos últimos anos também se destaca como cluster turístico da região, contribuindo para colocar ainda mais em relevo a Rota das Emoções (Silva, Hoffmann \& Costa, 2020).

\subsection{Estratégias adotadas e implementadas pelas empresas para o crescimento do setor pós- pandemia}

O Quadro 13 traz em seu bojo as estratégias adotadas e implementadas pelas empresas investigadas para o crescimento do setor do turismo pós-pandemia.

Quadro 13 - Estratégias adotadas e implementadas pelas empresas para o crescimento do setor pós pandemia

\begin{tabular}{|c|c|c|}
\hline Empresa A & Empresa B & Empresa C \\
\hline $\begin{array}{l}\text { "Bom, o fator primordial é o que } \\
\text { a gente vem discutindo sempre, } \\
\text { garantir os protocolos de } \\
\text { segurança para que o cliente se } \\
\text { sinta seguro ao viajar, enquanto } \\
\text { não existe uma vacina, teremos } \\
\text { de trabalhar com uma quantidade } \\
\text { reduzida de pessoas uso de } \\
\text { máscara, álcool em gel, limpeza } \\
\text { total dos veículos. Vamos seguir } \\
\text { de forma muito responsável os } \\
\text { protocolos e mostrar isso para o } \\
\text { cliente para que ele veja e se sinta } \\
\text { convidado a viajar" (E1). }\end{array}$ & $\begin{array}{l}\text { "A divulgação do destino que já } \\
\text { era feito, mas que deve continuar } \\
\text { sendo nosso carro chefe, todos } \\
\text { unidos divulgando a região e os } \\
\text { novos procedimentos adotados } \\
\text { utilizando todo o recomendado, } \\
\text { com álcool gel, mascará, redução } \\
\text { da capacidade de passageiros no } \\
\text { veículo" (E2). }\end{array}$ & $\begin{array}{l}\text { "Acredito fortemente no } \\
\text { marketing como uma estratégia } \\
\text { para apresentar o nosso serviço } \\
\text { dentro das normas de segurança, } \\
\text { mostrando que o cliente está } \\
\text { seguro e assim ele vai saber que } \\
\text { pode investir em nosso serviço, } \\
\text { eu acredito muito que as } \\
\text { empresas têm que trabalhar muito } \\
\text { isso, medidas de segurança e } \\
\text { marketing. Enquanto não existir a } \\
\text { vacina ninguém está seguro, } \\
\text { então temos que buscar todas as } \\
\text { estratégias possíveis de } \\
\text { segurança para o novo normal" } \\
\text { (E3). }\end{array}$ \\
\hline
\end{tabular}

Fonte: Dados da pesquisa.

De maneira geral, os entrevistados são unanimes em afirmar que a estratégia, para o momento é a segurança dos seus respectivos clientes, uso de máscara, álcool em gel, higienização (Coelho \& Mayer, 2020) dos veículos, redução da capacidade de passageiros por veículo. Além disso, o respondente E3 enfatiza adotar o fomento das estratégias de marketing para capitalizar mais clientes. De certa forma, os entrevistados, ainda continuarão priorizando 
Ribeiro, H. C. M., \& Moreira, A. A. A. P. (2021, maio/ago.). COVID-19: efeitos e implicações ocorridos no turismo da rota das emoções localizada no nordeste do Brasil

o uso de estratégias não farmacêuticas para o pós-pandemia (Manchein et al., 2020; Senhoras \& Nascimento, 2020).

Tal fato pode ser em decorrência de que, enquanto não houver uma vacina para controlar a pandemia (Kuwahara, Kuroda \& Fukuda, 2020; Nicola et al., 2020), prospectar estratégias (Ribeiro \& Forte, 2019) pode ser um risco formular estratégias para pós pandemia. Excetuandose adotar e implementar estratégias voltadas ao marketing como dito pelo respondente E3, pois, para o setor de turismo as estratégias de marketing podem contribuir para melhorar a performance de mercado das empresas turísticas (Sarquis et al., 2015), inclusive para pós COVID-19.

No estudo de Sarquis et al. (2015) analisaram as estratégias de marketing aplicadas no setor de serviços de agências de viagens/turismo no Estado de Santa Catarina. Os resultados apontam que a grande maioria das agências pesquisadas utiliza estratégias de marketing interno, externo, interativo e que as agências de porte médio utilizam com maior frequência a maioria das estratégias de marketing mensuradas.

\section{Considerações finais}

O objetivo deste trabalho científico foi estudar os efeitos e as implicações ocorridas no destino turismo da Rota das Emoções localizada no Nordeste do Brasil em decorrência da pandemia do COVID-19. Metodologicamente, utilizou-se a abordagem qualitativa, por meio do método do estudo de caso múltiplo em três Empresas de Passeio/Receptivos (uma de cada estado) que compõem a Rota das Emoções, Ceará, Maranhão e Piauí. Para análise dos dados enfocou-se a triangulação (entrevistas, documentos e observações) além da análise intercasos fundamentado no estudo de Miles e Huberman (1994).

Os resultados apontam, de acordo com as entrevistas, que o setor do turismo da região da Rota das Emoções foi extremamente prejudicado por contado do advento da pandemia do COVID-19, o setor em questão foi um dos primeiros a ter suas atividades suspensas e por consequência será um dos últimos a retomar, são mais de 90 dias parados sem realizar suas operações. Para uma empresa se manter nesse panorama fazem-se necessários inúmeros esforços, uma medida de emergência utilizada por muitas empresas do setor foi à suspensão de contrato que deu ao colaborador a garantia de dois meses em casa recebendo seu salário apesar das reduções.

Mesmo com a medida adotada foi inevitável conter os impactos como a perda de clientes, o cancelamento de viagens, a postergação de viagens, as demissões, a diminuição da 
Ribeiro, H. C. M., \& Moreira, A. A. A. P. (2021, maio/ago.). COVID-19: efeitos e implicações ocorridos no turismo da rota das emoções localizada no nordeste do Brasil

receita e os prejuízos diversos. Contudo, as empresas objeto de estudo, buscam por meio e respeitando os protocolos de segurança, continuar os negócios nesse "novo normal" por meio de estratégias, como por exemplo, fomentar o marketing (Sarquis et al., 2015). Mas de certa forma, para os entrevistados, até prospectar um cenário (Ribeiro \& Forte, 2019) para póspandemia é meio complexo, visto que, para todos, só será possível após o surgimento de uma vacina (Kuwahara, Kuroda \& Fukuda, 2020; Nicola et al., 2020) que possa com isso viabilizar e novamente tangibilizar estratégias mais robustas e concretas para retomar os negócios do turismo da região.

Os respondentes também afirmaram que, a localidade da Rota das Emoções é propensa a grandes "voos", visto que, é uma área turística bastante visitada por turistas locais e, sobretudo por turistas estrangeiros. E, por ser um cluster turístico (Sohn et al., 2017) forte, poderá impactar positivamente na retomada mais rápida dos negócios pós-pandemia, pois, como ocorre em outros clusters no Brasil e no mundo, as empresas que compõem a Rota das Emoções são parceiras e tem uma forte conexão de complementariedade (Mazaro \& Varzin, 2008; Sohn, Silvestrini, Fiuza \& Limberger, 2017), e isso deve-se por ter sido o primeiro consórcio interestadual de turismo do Brasil, otimizando assim sua operacionalidade (Silva, Hoffmann \& Costa, 2020).

Ainda não é possível prever as reais consequências da pandemia no setor turístico, o que é certo é que a pandemia está impondo aprendizados para todas as áreas que oferecem serviços, sendo que o setor do turismo deverá se reinventar para poder sobreviver, e certamente o caminho da sustentabilidade pós-coronavírus deverá que ser trilhado.

Conclui-se de maneira macro neste estudo os efeitos e as implicações ocorridas no destino turismo da Rota das Emoções localizada no Nordeste do Brasil em decorrência da pandemia do COVID-19, viabilizando com isso melhor entender o que de fato a pandemia impactou no cluster da Rota das Emoções. Podendo com isso tirar informações e compreensões a cerca desse evento sem precedentes no mundo. Por meio das falas dos entrevistados é possível também se concluir que esse vírus invisível trouxe ao mercado o medo e incerteza aliados as questões financeiras, porque mesmo após a vacina muitos consumidores precisaram de um tempo para reestabelecer suas finanças e confiar que estão seguros para viajar novamente.

Os conhecimentos manifestados aqui, de certa forma contribuem para saber que nenhum negócio, em especial no ramo do turismo, é de fato pleno, forte, perpetuo, visto que, os riscos sempre poderão ocorrer, e, está preparado para possíveis riscos, como o caso do COVID-19, é quase que impensável, mas que, infelizmente ocorreu, e que agora, as empresas objeto de 
Ribeiro, H. C. M., \& Moreira, A. A. A. P. (2021, maio/ago.). COVID-19: efeitos e implicações ocorridos no turismo da rota das emoções localizada no nordeste do Brasil

estudo, juntamente com suas parceiras precisam se ajudar de maneira mútua e mais ainda integrada para conseguirem sair desse precipício.

A busca por alternativas que os gestores dos destinos turísticos nesse momento de pandemia buscarem para se reinventar, além das determinadas, através de normativas do governo federal como a suspensão contratual temporária, subsidiada pelo governo que garanta os empregos, pode ser ações de responsabilidade social, que demonstrem seu papel social junto as comunidades onde estão inseridas.

Este estudo traz a baila contribuições para o melhor entendimento, compreensão e respeito para com o esse vírus tão destrutivo para muitos negócios, e de como deve-se ser enfrentado, com humildade, protocolos de segurança, ajuda mútua, respeito, com estratégias de higienização, cuidado com os clientes, cuidado com os colaboradores, cuidado com as empresas parceiras, mas sobretudo, cuidado com o setor do turismo da Rota das Emoções, pois, quando a pandemia acabar, continuará sendo referência no Nordeste do Brasil (Costa, Nascimento, Hoffmann \& Silva, 2017; Silva, Hoffmann \& Costa, 2020).

Esse estudo limitou-se em focar nas empresas de passeio da Rota das Emoções, contudo, tanto a questão de pesquisa, como também o objetivo do estudo foi respondido e alcançado respectivamente. Como sugestão para estudo futuros, aconselha-se replicar este estudo, alargando o número de empresas que compõem a Rota das Emoções; ou alargar o número de entrevistas, enfocando outros stakeholders que fazem parte do negócio do setor turístico da região; e enfocar a pesquisa por meio de uma abordagem quantitativa para investigar os resultados antes e pós-pandemia em uma amostra de empresas que são nativas da Rota das Emoções.

\section{Referências}

Acter, T., Uddin, N., Das, J., Akhter, A., Choudhury, T. R., \& Kim, S. (2020). Evolution of severe acute respiratory syndrome coronavirus 2 (SARS-CoV-2) as coronavirus disease 2019 (COVID-19) pandemic: A global health emergency. Science of the Total Environment, 730, 1-19. DOI: https://doi.org/10.1016/j.scitotenv.2020.138996.

Aguiar, E. P. S., \& Melo, S. M. C. de. (2020). Turismo e inovação territorial: Um olhar na perspectiva gastronômica. Research, Society and Development, 9(7), 1-20. DOI: https://doi.org/10.33448/rsd-v9i7.3670.

Barreto, R. de O.; Paula, A. P. P. de. (2014). "Rio da Vida Coletivo": empoderamento, emancipação e práxis. Revista de Administração Pública, 48(1), 111-130. DOI: https://doi.org/ 10.1590/S0034-76122014000100005. 
Ribeiro, H. C. M., \& Moreira, A. A. A. P. (2021, maio/ago.). COVID-19: efeitos e implicações ocorridos no turismo da rota das emoções localizada no nordeste do Brasil

Baggio, R. (2020). Tourism destinations: A universality conjecture based on network science. Annals of Tourism Research, 82, 1-23. DOI: https://doi.org/0.1016/j.annals.2020.102929.

Barros, T. F., \& Campomar, M. C. (2018). O trade marketing e suas atividades: estudo de casos no setor farmacêutico. Revista de Gestão em Sistemas de Saúde, 7(3), 297-313. DOI: https://doi.org/10.5585/rgss.v7i3.448.

Bezerra, A. C. V., Silva, C. E. M. da, Soares, F. R. G., \& Silva, J. A. M. da. (2020). Fatores associados ao comportamento da população durante o isolamento social na pandemia de COVID-19. Ciência \& Saúde Coletiva, 25, 2411-2421. DOI: https://doi.org/10.1590/141381232020256.1.10792020.

Carbone, F. (2020). Tourism Destination Management Post COVID-19 Pandemic: a new humanism for a Human-Centred Tourism (Tourism 5.0). World Tourism, Health Crisis and Future: Sharing Perspectives, 43-55.

Castro, J. M. de, Diniz, D. M., Duarte, R. G., Dressler, M., \& Carvalho, R. B. de. (2013). Fatores determinantes em processos de transferência de conhecimentos: um estudo de caso na Embrapa Milho e Sorgo e firmas licenciadas. Revista de Administração Pública, 47(5), 1283-1306. DOI: https://doi.org/10.1590/S0034-76122013000500010.

Castro, M. de, Bulgacov, S., \& Hoffmann, V. E. (2011). Relacionamentos interorganizacionais e resultados: estudo em uma rede de cooperação horizontal da região central do Paraná. Revista de Administração Contemporânea, 15(1), 25-46. DOI: https://doi.org/10.1590/S1415-65552011000100003.

Cepeda, G., \& Martin, D. (2005). A review of case studies publishing in Management Decision 2003-2004: guides and criteria for achieving quality in qualitative research. Management Decision, 43(6), 851-876. DOI: https://doi.org/10.1108/00251740510603600.

Coelho, M. de F., \& Mayer, V. F. (2020). Gestão de serviços pós-covid: o que se pode aprender com setor de turismo e viagens? Revista Eletrônica Gestão \& Sociedade, 14(39), 3698-3706. DOI: https://doi.org/10.21171/ges.v14i39.3306.

Costa, H. A., Nascimento, E. P. do, Hoffmann, V. E., \& Silva, D. L. B. da. ¿Por qué cooperan las micro y pequeñas empresas turísticas? Estudios y Perspectivas en Turismo, 26(4), 781803.

Cunha, L. T. da, Sá de Abreu, M. C., \& Cruz, L. B. (2015). Visão comparativa das estratégias climáticas adotadas por multinacionais do setor de alumínio no Canadá e no Brasil. Gestão \& Produção, 22(3), 495-507. DOI: https://doi.org/10.1590/0104-530X1183-14.

Durante, D. G., Veloso, F. R., Machado, D. Q., Cabral, A. C. A., \& Santos, S. M. (2019). Aprendizagem organizacional na abordagem dos estudos baseados em prática: revisão da produção científica. Revista de Administração Mackenzie, 20(2), 1-28. DOI: https://doi.org/10.1590/1678-6971/eramg190131. 
Ribeiro, H. C. M., \& Moreira, A. A. A. P. (2021, maio/ago.). COVID-19: efeitos e implicações ocorridos no turismo da rota das emoções localizada no nordeste do Brasil

Farzanegan, M. R., Gholipour, H. F., Feizi, M., Nunkoo, R., \& Andargoli, A. E. (2020). International tourism and outbreak of coronavirus (covid-19): a cross-country analysis. Journal of Travel Research, 1-6. DOI: https://doi.org/10.1177/0047287520931593.

Figueira, L. M., Baptista, C., Santos, N., \& Dionísio, M. (2020). Turismo e Crise Sanitária Mundial: um olhar sobre a adaptação resiliente. World Tourism, Health Crisis and Future: Sharing Perspectives, p. 119-140, 2020.

Freitas, A. F. de, \& Freitas, A. F. de. (2013). Análise institucional de mudanças organizacionais em um sistema cooperativo de crédito solidário em Minas Gerais. Revista de Administração Pública, 47(4), 999-1019. DOI: https://doi.org/10.1590/S003476122013000400009.

Froehlich, C. (2014). Sustentabilidade: Dimensões e métodos de mensuração de Resultados. Revista de Gestão do Unilasalle, 3(.2), 155-168. DOI: https://doi.org/10.18316/1316.

Garkalins, C. (2020). O caminho da sustentabilidade pós-coronavirus. Recuperado em: https://brasilturis.com.br/o-caminho-da-sustentabilidade-pos-coronavirus/

Godoy, A. S. (2006). Estudo de caso qualitativo. In C. K. Godoi, R. B. S. Melo, \& A. B Silva (Org.), Pesquisa qualitativa em estudos organizacionais: paradigmas, estratégias e métodos (pp. 115-146). São Paulo: Saraiva.

Gomes, E. L., Gândara, J. M., \& Ivars-Baidal, . A. (2017). É importante ser um destino turístico inteligente? A compreensão dos gestores públicos dos destinos do Estado do Paraná. Revista Brasileira de Pesquisa em Turismo, 11(3), 503-536. DOI: https://doi.org/10.7784/rbtur.v11i3.1318.

Gossling, S., Scott, D., \& Hall, C. M. (2020). Pandemics, tourism and global change: a rapid assessment of COVID-19. Journal of Sustainable Tourism, 1-20. DOI: https://doi.org/10.1080/09669582.2020.1758708.

Gouvêa, M. A., Onusic, L. M., \& Mantovani, D. M. N. (2016). Qualidade e lealdade ao curso no ensino superior. Revista de Administração da UFSM, 9(1), 26-45. DOI: https://doi.org/10.5902/19834659\%207690.

Hall, C. M., Scott, D., \& Gössling, S. (2020). Pandemics, transformations and tourism: be careful what you wish for. Tourism Geographies: An International Journal of Tourism Space, Place and Environment, 1-22. DOI: https://doi.org/10.1080/14616688.2020.1759131.

Karim, W., Haque, A., \& Anis, Z. (2020). The Movement Control Order (MCO) for COVID19 crisis and its impact on tourism and hospitality sector in Malaysia. International Tourism and Hospitality Journal, 3(2), 1-7. DOI: https://doi.org/10.37227/ithj-2020-02-09.

Khan, N., Hassan, A. U., Fahad, S., \& Naushad, M. (2020). Factors affecting tourism industry and its impacts on global economy of the world. Available at SSRN 3559353, 1-32. Recuperado em: < https://www.researchgate.net/profile/Shah-Fahad21/publication/340171808_Factors_Affecting_Tourism_Industry_and_Its_Impacts_on_Glo 
Ribeiro, H. C. M., \& Moreira, A. A. A. P. (2021, maio/ago.). COVID-19: efeitos e implicações ocorridos no turismo da rota das emoções localizada no nordeste do Brasil

bal_Economy_of_the_World/links/5e8636d692851c2f527792dc/Factors-Affecting-

Tourism-Industry-and-Its-Impacts-on-Global-Economy-of-the-World.pdf> .

Kuwahara, K., Kuroda, A., \& Fukuda, Y. (2020). COVID-19: Active measures to support community-dwelling older adults. Travel Medicine and Infectious Disease. DOI:

https://doi.org/10.1016/j.tmaid.2020.101638.

Lacruz, A. J., Américo, B. L., \& Carniel, F. (2017). Teoria ator-rede em estudos organizacionais: análise da produção científica no Brasil. Cadernos EBAPE.BR, 15(3), 574598. DOI: https://doi.org/10.1590/1679-395157007.

Lima, D. L. F., Dias, A. A., Rabelo, R. S., Cruz, I. D. da, Costa, S. C., Nigri, F. M. N., \& Neri, J. R. (2020). COVID-19 no estado do Ceará, Brasil: comportamentos e crenças na chegada da pandemia. Ciência \& Saúde Coletiva, 25(5), 1575-1586. DOI:

https://doi.org/10.1590/1413-81232020255.07192020.

Manchein, C., Brugnago, E. L., Silva, R. M. da, Mendes, C. F. O., \& Beims, M. W. (2020). Strong correlations between power-law growth of COVID-19 in four continents and the inefficiency of soft quarantine strategies. Chaos Na Interdisciplinary Journal of Nonlinear Scienca, 20(40), 1-10. DOI: https://doi.org/10.1063/5.0009454.

Marivate, V., \& Combrink, H. M. (2020). A Framework for sharing publicly available data to inform the COVID-19 Outbreak in Africa: A South African case study.

arXiv:2004.04813v1 [cs.CY]. Recuperado em: < https://www.researchgate.net/profile/Herkulaas-

Combrink/publication/340297878_Coronavirus_disease_COVID-19_case_data__South_Africa/links/5e9405fea6fdcca78911b2c0/Coronavirus-disease-COVID-19-casedata-South-Africa.pdf>.

Mazaro, R. M., \& Varzin, G. (2008). Modelos de competitividad para destinos turísticos en el marco de la sostenibilidad. Revista de Administração Contemporânea, 12(3), 789-809. DOI: https://doi.org/10.1590/S1415-65552008000300009.

Melo, R. de S., Monteiro, M. do S. L., \& Brito, A. S. (2018). Desenvolvimento turístico e sustentabilidade na unidade de conservação APA do Delta do Parnaíba (PI). Revista Brasileira de Ecoturismo, 11(3), 335-361. DOI: https://doi.org/10.34024/rbecotur.2018.v11.6686.

Menegaki, A. N. (2020). Hedging feasibility perspectives against the COVID-19 in the international tourism sector. Recuperado em: < file:///C:/Users/hcmri/Downloads/preprints202004.0536.v1\%20(2).pdf>.

Mercado, L. P. L. (2016). Metodologias de ensino com tecnologias da informação e comunicação no ensino jurídico. Avaliação: Revista da Avaliação da Educação Superior (Campinas), 21(1), 263-299. DOI: https://doi.org/10.1590/S1414-40772016000100013.

Miles, M. B., \& Huberman, M. A. (1994). Qualitative data analysis: an expanded sourcebook. Sabe: Thousand Oaks. 
Ribeiro, H. C. M., \& Moreira, A. A. A. P. (2021, maio/ago.). COVID-19: efeitos e implicações ocorridos no turismo da rota das emoções localizada no nordeste do Brasil

Munck, L., Munck, M. G. M., \& Souza, R. B. de. (2011). Gestão de pessoas por competências: análise de repercussões dez anos pós-implantação. Revista de Administração Mackenzie, 12(1), 4-52. DOI: https://doi.org/10.1590/S1678-69712011000100002.

Nicola, M., O`Neill, N., Sohrabi, C., Khan, M., Agha, M., \& Agha, R. (2020). Evidence based management guideline for the COVID-19 Pandemic - review article. International Journal of Surgery. DOI: https://doi.org/10.1016/j.ijsu.2020.04.001.

Oliveira, L. A. de, \& Arantes, R. de A. (2020). Neighborhood effects and urban inequalities: the impact of Covid-19 on the periphery of Salvador, Brazil. City \& Society. DOI: https://doi.org/10.1111/ciso.12266.

Paiva Júnior, F. G. de, Leão, A. L. M. de S., \& Mello, S. C. B. de. (2011). Validade e confiabilidade na pesquisa qualitativa em administração. Revista de Ciências da Administração, 13(31), 190-209. DOI: https://doi.org/10.5007/21758077.2011v13n31p190.

Rey, F. G. (2005). Pesquisa qualitativa e subjetividade: os processos de construção da informação. São Paulo: Pioneira Thomson Learning, 2005.

Ribeiro, H. C. M., \& Forte, S. H. A. C. (2019). A Média de Utilização das Estratégias pelos Programas de Stricto Sensu das Instituições do Brasil da Área de Administração Pública e de Empresas Ciências Contábeis e Turismo frente aos Cenários Prospectados para o Período de 2019 a 2030. Revista Ibero-Americana de Estratégia, 18(4), 535-555. DOI: https://doi.org/10.5585/riae.v18i4.13909.

Ribeiro, H. C. M. (2014). O envolvimento da governança corporativa, sob a ótica da teoria dos stakeholders, na gestão e no controle das entidades esportivas. Tese (Doutorado em Administração), UNINOVE, São Paulo.

Romão, F. M. da S. (2020). O impacto do COVID-19 no Turismo Receptivo - a Perspectiva da HighSun DMC. World Tourism, Health Crisis and Future: Sharing Perspectives, p. 5763, 2020.

Santos, F. R. dos, Ribeiro, L. C. de S., \& Silveira, E. J. G. da. (2018). Caracterização das atividades turísticas nos municípios brasileiros em 2015. Revista Brasileira de Pesquisa em Turismo, 12(2), 65-82. DOI: https://doi.org/10.7784/rbtur.v12i2.1419.

Santos, M. C. dos, Ribeiro, H. C. M. (2016). Vantagem competitiva no turismo à luz de sua produção acadêmica. Revista Eletrônica de Administração e Turismo, 8(4), 831-850, 2016. DOI: https://doi.org/10.15210/REAT.V8I4.6539.

Sarquis, A. B., Pizzinatto, N., Giuliani, A. C., \& Pontes, A. S. M. (2015). Estratégias de marketing: Estudo no setor de agências de viagens e turismo. Revista Brasileira de Pesquisa em Turismo, 9(2), 298-320. DOI: https://doi.org/10.7784/rbtur.v9i2.862.

Sayfullaev, J. (2020). Theoretical aspects of international tourism and its role in the global economy. Academicia: An International Multidisciplinary Research Journal, 10(3), 162169. DOI: https://doi.org/10.5958/2249-7137.2020.00066.X. 
Ribeiro, H. C. M., \& Moreira, A. A. A. P. (2021, maio/ago.). COVID-19: efeitos e implicações ocorridos no turismo da rota das emoções localizada no nordeste do Brasil

Senhoras, E. M., \& Nascimento, F. L. (2020). COVID-19: Enfoque Gerenciais na Saúde (Vol. 72). EdUFRR.

Sheresheva, M. Y. (2020). Coronavirus and tourism. Population and Economics, 4(2), 72-76. DOI: https://doi.org/10.3897/popecon.4.e53574.

Silva, D. L. B. da, Hoffmann, V. E., \& Costa, H. A. (2020). Confiança em redes de cooperação do turismo: análise de seu papel e elementos vinculados em Parnaíba, Piauí, Brasil. Revista Brasileira de Pesquisa em Turismo, 14(2), 9-29. DOI: https://doi.org/10.7784/rbtur.v14i2.1535.

Soares, T. C., \& Mazon, G. (2020). As ações de turnaround como possibilidade para o declínio organizacional em tempos de covid-19. REUNA, 25(2), 70-84, 2020. DOI: https://doi.org/10.21714/2179-8834/2020v25n2p70-84.

Sohn, A. P., Silvestrini, C., Fiuza, T. F., \& Limberger, P. F. (2017). Os elementos que caracterizam o Cluster Turístico em Balneário Camboriú, Santa Catarina, Brasil. Revista Brasileira de Pesquisa em Turismo, 11(1), 154-174. DOI: https://doi.org/10.7784/rbtur.v11i1.1201.

Souza, M. C. da C. (2021). O Estado e o turismo no Brasil: análise das políticas públicas no contexto da pandemia da COVID-19. Revista Brasileira de Pesquisa em Turismo, 15(1). 113. DOI: https://doi.org/10.7784/rbtur.v15i1.2137.

Souza, M. M. P. de, \& Carrieri, A. de P. (2011). Racionalidades no fazer artístico: estudando a perspectiva de um grupo de teatro. Revista de Administração de Empresas, 51(4), 382395. DOI: https://doi.org/10.1590/S0034-75902011000400006.

Trigo, L. G. G. (2020). Viagens e turismo: dos cenários imaginados às realidades disruptivas. Revista Brasileira de Pesquisa em Turismo, 14(3), 1-13. DOI: https://doi.org/10.7784/rbtur.v14i3.2107.

Vieira, D. P., Hoffmann, V. E., \& Alberton, A. (2018). Investimentos públicos, competitividade e desenvolvimento: um estudo em destinos turísticos brasileiros. Revista de Administração Pública, 52(5), 899- 917. DOI: https://doi.org/10.1590/00347612174959.

Volpi, Y. D., \& Paulino, S. R. (2019). A sustentabilidade em meios de hospedagem: enfoque na materialidade dos serviços. Desenvolvimento e Meio Ambiente, 52, 386- 410. DOI: https://doi.org/10.5380/dma.v52i0.59993.

Yin, R. K. (2010). Estudo de caso: planejamento e métodos (4a ed.). Porto Alegre: Bookman.

Zhai, Y., \& Du, X. (2020). Mental health care for international chinese students affected by the COVID-19 outbreak. The lancet. Psychiatry, 7(4), 22. DOI: https://doi.org/10.1016/S2215-0366(20)30089-4. 
Ribeiro, H. C. M., \& Moreira, A. A. A. P. (2021, maio/ago.). COVID-19: efeitos e implicações ocorridos no turismo da rota das emoções localizada no nordeste do Brasil

Zhan, Q. Y., Niu, Y. N., Zhang, H. H., Zhang, S. H., Liu, H. Y., Dong, J. W., \& Li, H. J. (2019). The Overview of Global Development and Control of COVID-19. ICSES

Transaction on Evolutionary and Metaheuristic Algorithms, 10(150), 1-10. 